\title{
Las Naciones Unidas
}

\author{
(ESTRUCTURA.-OBRA.-JUICIO CRITICO)
}

por el Dr. JOSE PAREJA y PAZ SOLDAN

\section{LA CARTA DE SAN FRANCISCO}

Los Estados Unidos y las Potencias vencedoras convocaron la Conferencia de San Francisco, que se inauguró en abril de 1945, para estructurar las Naciones Unidas, aun antes que la guerra con las Potencias del Eje hubiera concluído. Fué un gran acierto del Presidente Roosevelt reunirla en ese momento. En esa forma quiso asegurar su éxito; pensó con razón que entonces era más fácil llegar a un acuerdo, como en efecto se logró y que habría sido mucho más difícil alcanzarlo cuando, asegurada la victoria, se habría roto la alianza que entonces ya se perfilaba inestable. Asimismo en esa oportunidad fué más fácil obtener la aprobación del Senado norteamericano antes que razones de política interna hicieran más controversible la Carta y más difícil su aprobación parlamentaria. En ese sentido el Presidente Roosevelt aprovechó la experiencia del Convenant de la Liga de las Naciones y no incurrió en los errores del Presidente Wilson en 1920. Resultó entonces el portavoz de la esperanza y de la ilusión de todos los pueblos de la tierra que aspiraban a una paz efectiva y a una organización que la asegurase.

La Segunda Guerra Mundial ha dejado un doble legado: las Naciones Unidas y la Guerra Fría. Nadie puede predecir cuál de ambos determinará el futuro. Vivimos por eso en un mundo dividido con una paz inestable. Esperamos que, en las décadas que vendrán, se haga realidad la libertad dentro de la ley moral y bajo la égida de las Naciones Unidas. La Carta, no sólo un documento político sino también jurídico. es la fundación de la ley mundial, "the world low" y se ha encargado a las Naciones Unidas de hacer estudios $y$ fomentar el desarrollo del Derecho Internacional.

La Carta de San Francisco implicó los siquientes avances sobre los proyectos de Dumbarton Oaks, sin ser por cierto perfecta:

1 - Proteje la integridad territorial e independencia política de los Estados (art. $2^{\circ}$ inc. $4^{\circ}$ ).

2 -Declara que las soluciones pacíficas se ajustarán a los principios de la justicia $y$ del Derecho Internacional, (art. $2^{\circ}$, inc. $3^{\circ}$ ). 
$3^{\circ}$ - Admite la jurisdicción doméstica y se prohibe a la Organización intervenir en los asuntos internos de un Estado (art. $2^{\circ}$ inc. $7^{\circ}$ ) (1);

$4^{9}$-Reconoce el derecho de la Asamblea General de discutir cualquier asunto, aunque no puede decidir sobre los que son de la competencia del Consejo de Seguridad (art. $11^{\circ}$ inc. $2^{\circ}$ );

$5^{\circ}$-Admite la existencia de los Acuerdos Regionales y los incorpora al engranaje de la Organización (Cap. VIII). (2)

6 - -Acepta el derecho de propia defensa en el caso que el Consejo de Seguridad quede paralizado por el veto (art. 51);

$7^{\circ-D e d i c a}$ todo un capítulo al Consejo de Tutela y a la Administración Fiduciaria Internacional (Cap. XIII):

8.-Contiene un amplio capítulo sobre la importancia de los problemas sociales y económicos en tanto que el acento en los proyectos de Dumbarton Oaks estaba en la seguridad militar.

La Conferencia de San Francisco implicó, pues, un progreso evidente sobre los Proyectos de Dumbarton Oaks salvo en el asunto del veto, ya que se mantuvo inconmovible la fórmula de Yalta con la única excepción, al final, (que Roosevelt arrancó a Stalin) respecto a que los Estados que son parte de una controversia, así fueran miembros permanentes del Consejo, se abstendrían de votar. (3)

La aceptación de los Pactos Regionales ha permitido a los Estados Americanos ingresar en las Naciones Unidas sin renunciar a los acuerdos de Chacultepec de 1945 relativos a la seguridad del Hemisferio Occidental y que forma la base del Tratado de Asistencia Mutua de Río Janeiro de 1947, haciendo compatible las obligaciones de esos Pactos con las de la Carta de las Naciones Unidas.

El espíritu de las Naciones Unidas es, pues, favorecer el regionalismo en sus diversos aspectos -político, económico, jurídico y culturaldentro de las Naciones Unidas y de los órganos específicos regionales así como las Conferencias Interamericanas. La Carta reconoce, plenamente, todo

(1) El Delegado español José F. de Lequerica, una de las más brillantes personalidades en las Naciones Uridas, afirmó en una intervención en la XI Asamblea General, que esta disposición era el cinturón de castidad que protegía a los Estados contra violaciones e interferencias en su soberanía por otros Estados o por la propia Organización.

(2) El Comité Jurídico Interamericano había insistido en que la futura Organización Mundial se basara en la ley internacional; que ella debería conciliar el principio del universalismo con la existencia de agrupaciones regionales mediante los vínculos naturales de la solidaridad $\mathrm{Y}$ de los intereses comunes $\mathrm{Y}$ que podrian adoptar reglas particulares estableciendo determinadas relaciones entre sis miembros en asuntos que no afecten el conjunto de la comunidad internacional.

(3) Las propuestas de Dumbarton Oaks sometían totalmente los grupos regionales al Consejo de Seguridad y su acción podía quedar paralizada por el Veto. Tampoco definían lo que entendian por "acuerdo regional".

Las naciones latinoamericanas reaccionaron vivamente contra ese control $\mathrm{Y}$ sobre todo contra el riesgo que Rusia pudiera intervenir en los asuntos americanos, cuýa resolución debe corresponder primariamente a los paises americanos. 
regionalismo que tenga como objetivo el mantenimiento de la paz internacional y ha puesto especial énfasis en la utilidad de una cooperación entre los: Estados cuyos intereses similares se vean favorecidos por la adopción de. acuerdos regionales a los que dedica su capítulo VIII.

Las contribuciones principales del grupo latinoamericano en las $\mathrm{Na-}$ ciones Unidas se han referido a los siguientes puntos:

Respeto a la personalidad e independencia de los Estados;

Estricta observancia de los Tratados y compromisos internacionales:

Régimen de consulta para la solución pacífica de las controversias;

Cumplimiento de los Derechos Humanos;

Lucha contra el Colonialismo;

Admisión de nuevos miembros para hacer efectiva la universalidad de: las Naciones Unidas;

Frente común en la lucha contra el comunismo;

Condenación de la agresión.

Los antecedentes inmediatos de la Carta de las Naciones Unidas han sido la Carta del Âtlóntico (1942), las Declaraciones de Moscú (1943) y de Yalta (1945) y los Proyectos de Dumbarton Oaks (1944).

La Carta es un tratado, un texto legal, pero también un documento político en que los Representantes de todas las Naciones expresaron y concretaron sus aspiraciones, ideales y convicciones morales y jurídicas. Es un Código de conducta, gobernando las relaciones de los Estados dentro de la. más grande comunidad de la Historia. Sus disposiciones han afectado, vitalmente, el destino de las naciones y la vida de millones de hombres. Así pues la Carta de San Francisco no sólo es el más cercano "approach" sino el comienzo de un mundo regido por el Derecho Internacional.

Los cínicos y los escépticos podrán decir que solo representan palabras y más palabras. Pero los grandes documentos como la Carta Magna, la Declaración Americana de la Independencia o los Derechos Humanos fueron, inicialmente, meras palabras $\mathrm{y}$ han hecho la grandeza de las naciones más que las flotas y ejércitos.

En resúmen, la Carta de San Francisco representa el esfuerzo consciente y plausible de crear la mejor de las organizaciones, dentro de lo posible y de las condiciones existentes, con las limitaciones impuestas por la realidad y dentro de la esperanza de canalizar las políticas nacionales a través de un sistema internacional. Un documento honesto con principios activos, ya que, como quería Hamilton, todo gobierno debe contener un principio activo. Las Naciones Unidas no son un superestado, sino una organización política. internacional con poderes específicos. No es tampoco ni un órgano judicial, ni una alianza política, aunque actúa de acuerdo con las exigencias de la justicia y del Derecho Internacional. 


\section{ONE WORLD, UN MUNDO}

El destacado historiador inglés Arnold Toynbee ha insistido en que la gran revolución del siglo $\mathrm{XX}$ no es el descubrimiento del motor a explosión o de la energía atómica - la que para el antiguo Rector de Harvard, Conant, es tan importante como la invención del fuego- sino que el mundo por el desarrollo de la técnica y de las comunicaciones, se ha vuelto más chico. En su iibro "One World", Wendel Wilkie - una de las más sugestivas personalidades del Patrido Republicano que, como candidato de su partido, se enfrentó, aunque sin éxito, al Presidente Roosevelt - refiriéndose a sus impresiones de un viaje a Rusia, China y Medio Oriente, llegaba a la conclusión que "la neta impresión de mi viaje fué nó de la lejanía sinó de la proximidad de un pueblo a otro y si yo hubiera tenido algunas dudas que el mundo se ha tornado interdependiente y pequeño, éste viaje me las habría disipado completamente". Interdependencia que también se extiende al campo económico, porque hoy en día ningún país puede producir todos los productos que necesita para su población, su defensa y su expansión. Y un mundo, (one world), regido por las Cuatro Libertades del Presidente Roosevelt: Independencia física y espiritual del hombre - Mejoramiento de su standard de vida - Igualdad de oportunidades - Paz basada en la justicia.

La catástrofe de las dos Grandes Guerras Mundiales de este siglo constituye una exigencia imperiosa hacia el universalismo $\mathrm{y}$ ha puesto en evidencia la indiscutible unidad del mundo. Y hoy día un conflicto secundario puede precipitar una tercera guerra mundial, con la amenaza de la exterminación o degeneración de nuestra especie por las armas nucleares.

Cuando las gentes entonces se preguntan: ¿para qué sirven las Naciones Unidas y las Organizaciones Internacionales?, la respuesta está dada en la sangre derramada, en los millones de víctimas y en la destrucción ocasionada por las querras de este siglo.

El siglo XIX fué un siglo de paz, con pocas guerras de esfera limitada, debido a que gozó de un orden internacional informal pero efectivo para el tiempo y las circunstancias, orden creado por los Tratados de Viena de 1814-15 y basado en lo que se llamó "el equilibrio de poder" y "el concierto europeo".

Pero el mundo del siglo $\mathrm{XX}$, sobre todo después de la aparición de Estados Unidos y Rusia y el descubrimiento de las armas nuclelares, ha variado radicalmente, es demasiado complejo y el orden internacional debe ser protegido por un sistema mundial organizado que es el único que puede conservarlo a largo plazo.

Las Naciones Unidas implican una ley unónimemente aceptada -la Carta-y una comunidad que es la Organización.

El Papa Pío XII, en su Mensaje de Pascua de Resurrección de 1957, ha recordado que los continentes, las naciones y los hombres viven ansiosos $\mathrm{y}$ confundidos en un mundo turbio, que todo se ha tomado provisional $\mathrm{y}$ relativo y que el error ha hecho esclavo al hombre. La raza humana parece 
infectada $y$ herida y su sangre circula con gran dificultad porque los hombres, las clases y los pueblos persisten en vivir divididos.

Pero en esa noche trágica hay claros síntomas de un mejor amanecer, anuncia el Papa, y hay la esperanza de poder recibir el beso de un nuevo y más espléndido sol en un nuevo día. Señalaba el Sumo Pontífice que la energía nuclear ha abierto una nueva edad $y$ un vasto horizonte de posibilidades de gran expansión técnica.

Como señaló también el gran Pontífice, en su radio-mensaje de Navidad de 1948, las Naciones Unidas deben ofrecer garantías para la seguridad de todos los pueblos y que sea la plena expresión de la solidaridad permanente en la paz y no la mera expresión de una efímera solidaridad en la guerra.

La Declaración de Moscú, de 30 de octubre de 1943, expresaba que los Cu,atro Grandes - Inglaterra, Estados Unidos, Rusia y China- reconocían "Ia necesidad de establecer tan pronto como sea posible, una organización internacional general fundada en el principio de la igualdad soberana de todos los Estados pacíficos, organización de la cual podrán ser miembros lodos los Estados pacíficos, grandes y pequeños, a fin de asegurar el mantenimiento de la paz y de la seguridad internacional". Y la Declaración de Teherán, de Roosevelt, Churchill y Stalin-1 ${ }^{\circ}$ de diciembre de 1943 -reafirmó la necesidad de la cooperación y activa participación de los pueblos grandes y pequeños que constituían la familia mundial de naciones democráticas.

\section{LAS NACIONES UNIDAS Y LOS PRINCIPIOS DE JUSTICIA}

El gran principio de la Carta de las Naciones Unidas es la justicia. Como dijera el año pasado el Secretario de Estado Foster Dulles, (1) las Naciones Unidas no solo buscan el carreglo pacífico de los problemas internacionales sino tratan también de lograr que esos arreglos se basen en la justicia $y$ en el derecho internacional. Su fin fundamental es el mantenimiento de la paz y de la seguridad internacional, pero respetándose los derechos de todas las naciones. Todas son iguales y la Asamblea General es un cuerpo democrático en que todos los Estados tienen oportunidad de ser oídos por el mundo entero y de dirigirse a la conciencia de la humanidad, evitándose injusticias y conjurándose conflictos. Ninguna nación por pequeña que sea puede dejar de influir en una recomendación, ni ninguna gran potencia, por poderosa que sea, puede ser completamente indiferente o ignorar las opiniones de las pequeñas naciones.

El poder o la riqueza no solo constituyen el criterio que alinea a las deleqaciones. Una Delegación que representa a una pequeña nación o a un Estado de poco poder militar - caso de India, Bélgica, Perú. Irlanda puede tener una situación de leader $y$ de gran irradiación. Las grandes personalidades en la Asamblea no son siempre precisamente las que pertenecen a las Delegaciones de Grandes Potencias.

(1) Discurso a los periodistas de la Associated Press reunldos en Convención en New York, 22 de abril de 1957. 


\section{LAS NACIONES UNIDAS Y LA PAZ (1)}

Cuando existe una disputa o un conflicto, las Partes interesadas deben tratar de hollar una solución por medio de negociaciones, comités de investigación, mediación, conciliación, arbitraje, solución judicial, recurso a las organizaciones regionales $\mathbf{u}$ otro medio pacífico que escojan. El Consejo de Seguridad puede investigar cualquier disputa o situación que pueda producir una fricción internacional o determinar el surgimiento de un conflicto que amenace la paz y la seguridad internacionales $y$, si persiste el problema, puede recomendar la adopción de procedimientos o métodos de arreglo ó un proyecto de acuerdo que considera apropiado. La Carta, sin embargo, con criterio realista acepta los acuerdos regionales y el derecho de defensa individual y colectivo.

Pero el Consejo no sólo puede recomendar sino también actuar. Según el Capítulo VII, cuando estima que existe una amenaza efectiva para la paz, una ruptura de la paz o una amenaza de agresión, puede hacer recomendaciones o decidir qué medidas deben tomarse para mantener o restaurar la paz internacional. Antes de llegar a esos extremos, puede llamar a las Partes interesadas para que cumplan con ciertas medidas provisionales para evitar que se agrave la situación. Finalmente las medidas que puede tomar el Consejo de Seguridad contra un Estado que ha roto la paz incluyen la interrupción de relaciones económicas y de las comunicaciones, ruptura de relaciones diplomáticas y lo más importante de todo, el uso de la fuerza. Las unidades militares, navales y de aviación serán proporcionadas por los Estados Miembros según las negociaciones que se haya hecho con el Consejo de Seguridad.

\section{LA LIGA DE LASS NACIONES, ORGANISMO EUROPEO}

La Liga de las Naciones - que funcionó de 1920 a 1939 -fué una institución europea por sus motivaciones y muY siglo XIX por sus ideas, expresando la convicción de los pueblos europeos que le incumbía la dirección y responsabilidad de los otros Continentes. Se le llamó, con cierta razón, un club anqlo-francés. Le faltó la decisión y la firmeza que demostraron las Naciones Unidas - al combatir la agresión de Corea, las guerrillas en Grecia o las tropas extranjeras en Irán- cuando se trató de detener la agresión del Japón contra la Manchuria en 1931, la de Alemania cuando ocupó militarmente la Renania y desconoció sus obligaciones para con el Tratado de Versalles en 1936 e hizo el Anchluss con Austria y cuando Mussolini se lanzó a la aventura de Abisinia en 1939.

Si la Liga de las Naciones hubiera tomado una actitud resuelta, la

(1) Cordel Hull en sus Memorias dice que, en la mañana del 31 de diciembre de 1941 , mientras Churchill tomaba un baño en la Casa Blanca, donde estaba hospedado, Roosevelt entró inopinadamente y le sugirió que la Declaración proyectada llevara el nombre de ' $\mathrm{Na}$. ciones Unidas" "The distinguished bather agreed and this the term United Nations came into boing". 
agresión continuada y en cadena de esos Estados totalitarios no habría conducido a la Segunda Guerra Mundial. (l) Cuando se quiso detener a esas fuerzas desatadas éstas ya habían ido demasiado lejos y tenían en pleno desarrollo sus planes de guerra.

La Liga impuesta por las Grandes Potencias, aceptada de mal grado por las Pequeñas, ante una opinión mundial poco preparada a las exigencias de una institución universal, tuvo como objetivo principal la necesidad de la seguridad colectiva y su política estaba determinada por las necesidades del "concierto europeo".

El Concierto Europeo dió un siglo de paz solo roto por las guerras de Crimea $\mathrm{Y}$ franco-prusiana. EI siglo XIX fué un siglo de consultas $\mathrm{Y}$ de congresos internacionales pero sin una organización internacional permanente, que se reunía sin periodicidad y solo actuaba por acuerdo unánime. Las Grandes Fotencias de entonces, que decidían los problemas internacionales eran Gran Bretaña, Francia, Rusia, Prusia, Austria y Saboya, que han quedado barridas ahora por la existencia de solo 2 Grandes - SuperpotenciasEstados Unidos y Rusia. Se realizaron los Congresos de Chaumont, Viena, Aix-la-Chapelle, Troppau, Labach, Verona, París, Berlín. También fue surgiendo una administración internacional con las Comisiones de los Ríos Internacionales, - Rhin, Danubio- y las organizaciones para los ferrocarriles, la Unión Postal Universal, la Oficina Internacional de Higiene, el sistema métrico intemacional y los congresos científicos.

En la Liga de las Naciones tenían asientos permanentes en el Consejo de Seguridad, Gran Bretaña, Francia, Italia, Japón, Alemania y Rusia.

Morgenthau en su libro "Politics among Nations", expresa que la Santa Alianza fué francamente un gobierno de las grandes potencias, la Liga de las Naciones un gobierno internacional de las Griandes Potencias con aviso y consejo de todos los Estados miembros en virtud del principio de la unanimidad y las Naciones Unidas es más bien como la liga, un gobierno internacional de las Grandes Potencias, pero con participación creciente de las Medianas y Pequeñas Naciones. Pero hay un contraste evidente entre las espectativas de la Carta y su realidad.

La Liga de las Naciones fracasó porque faltó el acuerdo de las Grandes Potencias, solo se basaba en lo que se llamaba "el concierto europeo", y nunca tuvo carácter universal, porque los Estados Unidos no particifaron en elia, no obstante haber nacido por la tenaz y generosa acción del Presidente Wilson, ya que el Senado norteamericano se negó a ratificar el Convenant y porque la Rusia Soviética, que vivía bajo terribles problemas internos de afirmación de su propio régimen comunista, le prestó una limitada cooperación $y$ tuvo una participación de segundo plano. Tenía razón el Canciller Soviético Litvinoff cuando afirmaba que la paz era indivisible y que los principios en que se basaba dicha paz también eran indivisibles. Es notorio el declinar político de Europa pese a su extraordinario flo-

(1) Si la Liga hubiera actuado en 1936, cuando la ocupación militar de la Renania con la decisión y rapidez de las Naciones Unidas cuando la opresión de Corea en noviembre de 1950, se habría evitado quizás la Segunda Guerra Mundial. 
recimiento cultural y a que sigue siendo gran centro del arte y de las letras. Europa ha sufrido, en carne propia, dos guerras mundiales con terribles batallas libradas en sus territorios, con sus casas y pueblos destruídos, desde el aire, por implacables bombardeos, sus élites diezmadas, sus juventudes destrozadas o agotadas por la violencia del conflicto; con Francía debatiéndose en una crisis política, con la liquidación del colonialismo y con la rreciente dependencia económica de otras regiones, como es el caso del petróleo: en el siglo XIX poseía todo el carbón que necesitaba. Ahora sus máquinas y sus tanques se mueven con petróleo traído del exterior y la última crisis del Canal de Suéz puso en evidencia cuán fuerte es esa dependencia. El eje político pasó del Mediterráneo al Atlántico y ahora al Pacífico, con sus dos únicas Grandes Potencias Mundiales que le son ribereñas: Estados Unidos y Rusia Soviética. La aventura de Suéz demostró que Francia e Inglaterra no pueden desafiar al mismo tiempo, a ambos países.

La Liga ofreció además una debilidad constitucional (no prohibía la guerra ni la ponía fuera de la ley) y una debilidad estructural pues mientras era predominantemente europea, el poder unido de Estados Unidos, Rusia y Japón era mayor. Comenzó muy alto pero pronto perdió fuerza y autoridad y se transformó en una institución sin eficiencia y sin prestigio. Las Naciones Unidas nacieron en medio de la Guerra Fría, pero su obra se viene afirmando de año en año; no ha sido una simple repetición de la Liga sinó un nuevo planteamiento en función de nuevos problemas y necesidades. No ha pasado - como en la antigua Liga- en la que los grandes problemas Inundiales se resolvían fuera de ella, sinó que son afrontados y resueltos dentro del marco de las Naciones Unidas. Esta no solo ha sobrevivido a los cambios ocurridos entre 1945 y 1957 -ruptura del sistema de alianza de la Segunda Guerra Mundial, la guerra fría, el advenimiento de la era atómica y de las armas nucleares, la rápida liquidación del Sistema Colonial, la afirmación internacional de nuevos pueblos como India y Egipto, el rechazo de la agresión (casos de Corea y Suez), crisis de nacionalismo (Líbano e Irag), sino que se ha ajustado a esos cambios y unificado las fuerzas morales del mundo. Las Naciones Unidas se han afirmado y crecido en inanticipados caminos como principal guardiana de la paz. Se trata de una dinámica sociedad internacional dentro de la cuai las naciones viven juntas por lazos visibles y tangibles, que se esfuerza por lograr la solución pacífica de las disputas y la promoción del desarme. Y si se produce la agresión y la violencia, cuenta con una maquinaria adecuada para detenerlas.

Finalmente, en la Carta se reconocen los Acuerdos Regionales. En el Convenant solo existía una referencia ambigua e impropia a los entendimientos regionales como la Doctrina de Monroe, la que nunca fue clarificada (no obstante que Costa Rica lo solicitó alguna vez), ni recibió ninguna implimentación.

La Liga de Naciones vivió cerca de 20 años, de 1920 a 1939. Pero le faltó decisión para afrontar $y$ resolver los grandes conflictos $Y$ hacer respetar sus decisiones, en que estriba quizás, la principal razón de su fracaso. Si se detiene al Japón cuando inició la agresión de la Manchuria en 1931 y más tarde, la guerra contra China, ○ a Italia cuando se lanzó 
a la conquista de Etiopía en 1935 o a Alemania cuando militarizó la Renania el año siguiente, forzó el Anchluss con Austria o conquistó Checoeslovaquia, la agresión continuadx y en cadena de esos Estados totalitarios no habría conducido a la Segunda Guerra Mundial. Cuando se les quiso detener ya habían ido demasirado lejos y sus leaders - Togo, Hitler, Mussclini- tenían ya en pleno desarrollo sus planes bélicos. Tuvo razón el Canciller soviético Litvinoff cuando afirmó que la paz era indivisible. Los principios en que se asentaba esa paz eran también indivisibles y debían basarse en la justicia y no en las situaciones cambiantes del equilibrio del poder. Esa es la gran diferencia entre la foltica de apaciguamiento que encarnó Chamberlain y que condujo al rendimiento de Munich en 1938, y los esfuerzos pacifistas que realizan las Naciones Unidas pero que sabe enfrentarse a la agresión cuando es necesario.

Respecto a las diferencias en la estructura entre la Liga de las Naciones y las Naciones Unidas se puede señalar que, en líneas generales. hay cierta similitud en su estructura: la Asamblea General, el Consejo de Seguridad y la Secretaría General. Pero en la Liga las funciones del Consejo y de la Asamblea no estaban claramente diferenciadas, en tanto que en las Naciones Unidas son definidas y diversas. En la Sociedad de Ginebra se necesitaba para la casi totalidad de las decisiones tanto en el Consejo como en la Asamblea, la unanimidad de los delegados presentes. (1)

En las Naciones Unidas, para que haya una decisión en el Consejo -salvo en meros asuntos de procedimiento que solo se necesita una mayoría simple- es necesaria una mayoría calificada de siete miembros incluyendo a los miembros permanentes; y un voto contrario de estos- el llamado veio- faraliza la resolución. La abstención o la ausencia no se considera voto negativo. En la Asamblea se requiere una mayoría de dos tercios de los vatantes para muchos asuntos, y simple para el resto, la reforma de In Carta. Los miembros permanentes del Consejo tienen derecho a impedir. En la Liga toda enmienda implicaba unanimidad de los miembros del Consejo y mayoría en la Asamblea.

Ia Carta de las Naciones Unidas consta de 111 artículos y un largo preámbulo sobre los Propósitos y Principios de la Organización. El Convenant de la Liga de las Naciones solo contenía 26 artículos.

El Convenant ignoró todo lo relativo a los problemas sociales y económicos, de gran importancia y relieve en la Carta y su Comisión de Man datos es distinta del Consejo de Tutela, el que tiene mayores poderes que aquella Comisión. La Corte Internacional de La Haya forma parte de ambas y eran idénticos su jurisdicción y procedimientos, pero en la Carta aparece más asociada a la obra de las Naciones Unidas.

(1) El principio de unanimidad sufrió varias modificaciones. En los Comités las resalur ciones se aprobaban por mayoría. En la Asamblea si se necesitaba la unanimidad, pero las Delegaciones que eran contrarias a una resolución, simplemente se abstenían. Finalmente se estableció una diferencia en el procedimiento: las decisiones de la Asamblea requerían sim. ple mayoría y las recomendaciones requerian unanimidad. 
Hace solo 40 años que los Estados Unidos entraron a la Primera Gran Guerra, esa guerra que no sólo destruyó, en palabras de Lloyd George, el orden establecido y la unidad de la civilización occidental sinó que dió nacimiento $\alpha$ un nuevo barbarismo en la forma del Bolchevismo y luego del Nazismo, cambios profundos que determinaron además la Segunda Guerra Mundial.

Esta liquidó a las Potencias Europeas como grandes Potencias Mundiales, acabó con el colonialismo, ha divido material y espiritualmente a Europa $y$ también al mundo en dos grandes poderes - Estados Unidos y Rusia Soviética- y precipitado la edad atómica con sus armas terriblemente destructoras; con la bomba atómica y la más peligrosa aun de hidrógeno; los bombarderos supersónicos, los intercontinentales guided missiles con cabezas atómicas explosivas, y luego, con el lanzamiento de satélites en el espacio sideral. El mundo, que ha sufrido tan terribiemente en esas dos grandes guerras, no podrá afrontar una tercera guerra.

La gran tarea de nuestra época es resolver el problema sustancial de asegurar la paz sin someterse a la esclavitud, de librarse de la aniquila. ción universal sin renunciar a la libertad. Hay que evitar a toda costa la guerra atómica y la destrucción en masa. El mundo libre debe disponer de un poder de represalia suficientemente fuerte para que el mundo comunista no se atreva a precipitar un ataque como el de Pearl Harbor, sin riesgo de sufrir, asimismo, su propia destrucción.

\section{LAS NACIONES UNIDAS Y EL ACUERDO DE LAS GRANDES POTENCIAS}

El principal objetivo de las Naciones Unidas fué el mantenimiento de la paz y de la seguridad internacional a través del gobierno internacional de las Grandes Potencias. Se partía de tres presupuestos: $1^{\circ}$ - - Las Grandes Potencias actuarón unidas, frente a cualquier amenaza de la paz sin consi derar la naturaleza del problema: 2\%-La sagacidad de las Grandes Poten cias permitirá resolver pacíficamente esos problemas, sin recurrir a la gue $\mathrm{rra}$; $3^{\circ}-\mathrm{La}$ amenaza de guerra no será suscitada por una gran potencia.

La experiencia ha demostrado lo contrario: las Grandes Potencias no han estado unidas ni actuado conjuntamente $y$ tienen intereses opues. tos y la situación es tan tensa que en cualquier momento puede desatarse la guerra.

La Carta, en abstracto, se orienta contra la agresión; pero, en concreto, las Naciones Unidas deberán luchar contra la agresividad rusa. Los soviéticos dijeron, en marzo de 1953, en la Asamblea General, que la Resolución Unión Pro Paz era un complot de Estados Unidos contra Rusia, pero expresaron en un lenguaje agresivo, una verdad cierta, pues era un cambio fundamental en la estructura de la Organización y en la balanza de funciones, desplazando la responsabilidad del mantenimiento de la paz al Consejo de Seguridad de la Asamblea General, para detener las amenazas y los actos agresivos de Rusia.

Se ha dicho que la nueva "Naciones Unidas" debe partir del hecho de la guerra fría entre las dos Grandes Superpotencias -Rusia y Estados 
Unidos- pues China nacionalista es un mero fragmento de nación y los poderes de Francia e Inglaterra se encuentran reducidos - para impedir que esa Guerra Fría se convierta en una Guerra efectiva y pueda lograr la paz que ahora sólo existe con temor y como esperanza.

Fenelón, (1) anticipándose a la actual realidad internacional, hacia en el siglo XVII el elogio del sistema de Dos Poderes iguales que mantuvieran el equilibrio del destino de la seguridad pública. Creía que era la situación más juiciosa y sagaz; todas las demás Potencias devendrían amigas, y cada uno de los dos sería cada día más fuerte, tendría más amigos y alianzas, ninguno abusaría de su superioridad por temor de irritar al otro, contentóndose con una aspiración de equidad.

Pero, para desgracia, el equilibrium pintado por Fenelón, no está dando resultados tranquilizadores en la rivalidad entre Estados Unidos y Rusia, ni ha creado una situación inestable debido al impacto de la guerra total, del nacionalismo ruso y de su agresividad sectaria-comunista y a la técnica de la guerra contemporánea.

Las Naciones Unidas fueron edificadas sobre la base esencial de la cooperación de las Grandes Potencias (2). No se puede nada sin ellas. Es una liga de naciones -grandes, medianas y pequeñas-amantes de la paz, cuya preservación depende, sobretodo, del acuerdo de las Grandes Potencias. Por eso, mientras no se modifique el régimen del veto, no podrá ser una fuerza operante contra los Grandes. El Consejo de Seguridad pudo actuar cuando la agresión de Corea, en junio y julio de 1950, por la ausencia temporal de Rusia. Más tarde, en noviembre, de ese año, la Asamblea General aprobó la célebre Resolución "Unión Pro Paz", que determina:

a).-La previsión que la Asamblea puede reunirse en 24 horas si el Consejo ha visto paralizado, por el veto, su responsabilidad primaria en el mantenimiento de la paz;

b).-Al reunirse la Asamblea, puede hacer recomendaciones a los Estados Miembros, Inchuyendo el empleo de fuerzas militares:

c).-Recomienda que cada Estado miembro disponga, en ese caso, de unidades armadas que puedan ponerse, rápidamente, a disposición de las Naciones Unidas;

d).-Establece una Comisión de Observación de la Paz (3) destinada $\alpha$ informar inmediatamente apenas surja un área de tensión internacional;

e).-Creó un Comité de Medidas Colectivas destinado a estudiar e informar sobre los medios $\mathrm{y}$ vías para fortalecer la paz internacional.

(1) Suplementa al Examen de Conciencia acerca de los deberes del Reino.

(2) En el cuento de George Orwell "Animal Farm" al final, los animales arrojan al único hombre que vive en la granja, Mr. Jones, y organizan la chacra solos diciendo: "Los de 4 pies (animales) son buenos, pero los de dos, 2 pies (los hombres), son malos. Así se podría decir: "Las Naciones Unidas son buenas, pero "the power politics" malo; excelente la Carta y el espíritu de las Naciones Unidas pero mala la política seguida en ella por las Grandes Potencias".

(3) La Comisión de Observación de la Paz aún continúa en funciones, aunque Rusia la objeta $y$ boycotea alegando que es contraria a la Carta. 


\section{CARACTERISTICAS BASICAS DE LAS NACIONES UNIDAS}

Como características básicas de las Naciones Unidas pademos señalar las siguientes:

1-. Un sistema de organización internacional, permáanente, universal y definitivo para lograr ciertos fines comunes por una acción internacional;

2 - Un órgano de seguridad internacional cuyo propósito, según el artículo $1^{\circ}$ de la Carta, es mantener la paz y la seguridad internacional a través de la seguridad colectiva;

$3^{\circ}$-Es la extensión y concreción de una alianza de la época de guerra que comenzó con la Carta del Atlóntico (14 de agosto de 1941), la Declaración de las Naciones Unidas ( $1^{\circ}$ de enero de 1942), la Conferencia de Moscú ( $1^{\circ}$ de noviembre de 1943), la Declaración de Teherán (1ํ de diciembre de 1943), las Proposiciones de Dumbarton Oaks (1944), la Conferencia de Yalta (1l de febrero de 1945) y la Conferencia de San Francisco (1945).

Las Naciones vencedoras en la Segunda Guerra Mundial representaban la piedra angular de la seguridad mundial; (1)

4 $\mathrm{O}-\mathrm{Es}$ una Asociación de Estados Miembros. No un superestado ni un gobierno mundial. Es un régimen en el cuarto nivel (local, regional, nacional, internacional) en una etapa rudimentaria. Las Naciones Unidas son el centro donde se armonizan las acciones de las naciones;

$5^{\circ}$ - Todos los Estados Miembros son iguales en representación y voto (sólo el Consejo de Seguridad, es una excepción a la regla general), pero ninguno puede intervenir en los asuntos internos-jurisdicción doméstica- de un Estado:

$6^{\circ}$-Las Naciones Unidas tienen personalidad internacional. Es algo más que una simple Asociación de Estados. Tiene una personería jurídica internacional; puede negociar y firmar Tratados; su sede general goza de derechos extraterritoriales y de un estatuto legal, y cuenta con una fuerza de emergencia, un staff y una bandera propia. La Corte Internacional de Justicia de La Haya, en un "avis consultatif", ha expresado que "bajo la ley internacional la Organización debe tener todos los poderes que aunque no expresamente propuestos en la Carta, le son otorgados por necesaria implicación por serle necesarios para el cumplimiento de sus deberes".

Prosiguen los contactos entre Este y Oeste y las Naciones Unidas sirven para mitigar y discutir los conflictos. Pero forzar una solución radical,

(I) El Dr. Víctor Andrés Belaúnde, de ingenio extraordinario $y$ brillante, ha expresado en uno de sus célebres apotegmas, celebrado $y$ festejado en los corredores de la Orga. nización, que la norma en las Naciones Unidas es que siempre desaparece algo: cuando hay un conflicto entre dos naciones pequeñas, desaparece el conflicto: cuando uno entre una nación grande $y$ otra pequeña, desaparece la pequeña nación y cuando hay un conflicto entre dos grandes potencias dsaparecen las Naciones Unidas! 
en esta etapa de la guerra fría y de la crítica situación internacional, solo conduciría a que desaparecierom las Naciones Unidas. Persiste la crisis internacional; pero también subsiste la Organización.

Las Naciones Unidas, directamente o a través de las agencias especializadas, se ha interesado en Ia vida social $y$ económica del mundo, los derechos humanos, el problema de los refugiados, la independencia de los territorios bajo tutela $y$ ha tenido una enorme influencia sobre la vida de los hombres del mundo entero en los campos de la producción alimentación, finanzas, salud y comunicaciones.

Las Naciones Unidas tienen por objetivo no solo hacer la vida de las naciones más segura y protegida sino también más productiva, con un afirmativo sentido de promover el bienestar general. La paz y seguridad interhacionales, el bienestar económico y el progreso social son sus grandes objetivos.

\section{LA ASAMBLEA GENERAL. - PRINCIPALES ATRIBUCIONES}

Las Naciones Unidas se componen de un grupo de órganos y agencias además de las comisiones, comités y conferencias especiales. Cinco cuerpos se designan en la Carta como "los principales órganos": la Asamblea General, el Consejo de Seguridad, el Consejo Económico y Social, el Consejo de Tutela y el Secretariado. A la Corte Internacional de Justicia se le designa como "el principal órgano judicial".

La Asamblea General funciona durante tres meses al año en sesiones ordinarias. Generalmente comienza sus sesiones el tercer martes de setiembre y termina en vísperas de Navidad. Habitualmente se reúne en Nueva York, en la sede general de la Organización; aunque en dos oportunidades - 1948 y 1951 - se ha reunido en París y la primera Asamblea, fué en Londres, en 1946. La Ãsamblea puede reunirse también para sesiones especiales con temario específico.

En la Asamblea están representados, en absoluto pié de igualdad, todos los Estados Miembros, con igual número de votos, - uno por país. Sus funciones - un poco extensas - son deliberativas ya que puede discutir y hacer recomendaciones sobre todos los asuntos que afectan la paz y la seguridad internacional y el gobierno del mundo con excepción tan sólo de los que son específicamente de la competencia del Consejo de Seguridad y mientras éste los esté examinando; constituyentes por que puede ampliár o modificar la Carta de las Naciones Unidas pero dentro de un proceso de mayorías $y$ de rectificaciones, establecido en la misma Carta: electorales pues elige al Secretario General de Ia Organización, a los Jueces de la Corte Internacional de Justicia de La Haya, a los Miembros no permanentes del Consejo de Tutela, del Consejo Económico y Social y

(1) En los últimos 150 años, la guerra generalizada determinó un intento de organización intemacional. La Santa Alianza siguió a las guerras napoleónicas; ló Ligá de las Naciones a la Primera Guerra Mundial Y las Naciones Unidas a la Segunda. 
otros Organismos de supervigilancia pues controla y regula los otros órganos de las Naciones Unidas $y$, como organismo central, recibe y considera los informes que se le presentan; $y$ financieras pues aprueba el presupuesto de la Organización y fija el régimen de cuoias. Pero sus principaies funciones son políticas como la consideración de los principics generales para mantener la paz y la cooperación internacionales; el desarme y la solución pacífica de los problemas internacionales, cualquiera que sea su origen y jurídicas pues debe impulsar el desarrollo del Derecho Internacional y su codificación, hacer efectivos los derechos humanos $y$ fomentar el pro greso cultural. económico, educativo y sanitario de los pueblos.

La Asamblea General está obligada a aprobar los asuntos importantes como los llama la Carta, por una mayoría calificada de dos tercios de los miembros presentes $y$ votantes (1).

Las resoluciones y recomendaciones que requieren esa mayoría estón enumeradas exhaustivamente en la Carta (2) y son:

las recomendaciones relativas al mantenimiento de la paz y de la seguridad internacionales;

la admisión de nuevos Miembros;

la supresión de los derechos y privilegios de algún Miembro o su expulsión;

las cuestiones relativas al funcionamiento de la administración fiducioria;

las cuestiones presupuestarias;

la elección de los Miembros Permanentes del Consejo de Seguridad, del Consejo Económico y Social y de los de Administración Fiduciaria; y

la reforma de la Carta de las Naciones Unidas y la convocatoria de una conferencia general y todos los demás asuntos relacionados con esa reforma (artículos 108 y 109).

Salvo esa mayoría calificada para determinados asuntos, el veto no funciona en la Asamblea. Todos los demás asuntos, incluyendo la determinación de los que deben resolverse por una mayoría calificada, se toman por mayoría simple.

La Ascamblea no toma resoluciones obligatorias sino recomendaciones. El cumplimiento colectivo de una decisión (enforcement action) de las Naciones Unidas sólo puede hacerlo el Consejo de Seguridad. Pero ningún Estado puede ignorar las decisiones de la Asamblea porque representan la opinión pública mundial y el sentimiento generalizado de las naciones. Puede dejar de cumplirlas, como en el doloroso caso de las recomendaciones sobre Hungría, pero se sitúa en una condición embarazosa y se pone al margen de la ley internacional.

Ia Asamblea General es el "meeting town of the world", el forum

(1) Las abstenciones no se computan de manera que los votos afirmativos deben $20 r$. cuando menos, el deble de los negativos para alcamar esa mayoría de dos tercios.

(2) Artículo 18, (inciso 29). 
mundial para debatir y exponer un parlamento internacional (1) donde se traton todas las cuestiones de interés mundial con plena libertad; donde se exponen, a plena luz, las quejas, temores y agravios, así como las esperanzas Y deseos $y$ donde ninguna nación puede bloquear una discusión ni prohibir las inclusión de un tema. Las resoluciones que adopta no son obligatorias ya que tiene poderes de recomendación $y$ de persuación $y$ no de coerción pero representan la fuerza moral, la fuerza de ios principios y la fuerza de la opinión pública mundicl. No puede mandar ni legislar sino someter, proponer y recomendar pero una recomendación puede ser más efectiva que una norma compulsiva porque detrás de ella, está el mundo entero.

Se censura a la Asamblea -a la cual confluyen las grandes personalidades pero también todas las vanidades del mundo- el exceso de discursos que repiten los mismos argumentos, "un gouvernement qui parle", los arrebatos de hipocrática indignación, su falta de sentido de la realidad y sus gestos teatrales, ya sea para la galería o para el record de las versiones, repitiéndose los mismos argumentos.

Es cierto que hay pérdida y desperdicio de tiempo pero los delegados que la integran son los mismos que forman los parlamentarios nacionales. Y el precio necesario para tener un gobierno libre, popular y repre sentativo es que sus asambleas no sean controladas, sometidas ni ordenadas aunque a veces, sean impetuosas o se prolonguen innecesariamente.

La Asamblea General puede reunirse extraordinariamente, a pedido del Consejo de Seguridad o de una mayoría de los Estados Miembros. Hasta ahora se han efectuado cinco reuniones extraordinarias. Dos de ellas (1947 y 1948) para la cuestión de Palestina; otras dos, concurrentemente en noviembre de 1956 para los asuntos de Hungría y de Suéz y la última, en agosto de 1958, para el problema de las tropas extranjeras en Líbano y Jordania.

La Resolución Unión Pro Paz varió las reglas tan solo 24 horas después de convocada, estableciendo una Comisión de Observación de la $\mathrm{P}_{\mathrm{az}}$ y recomendando a los Estados miembros que mantengan fuerzas adecuadas para acudir al llamado del Consejo de Seguridad o de la Asamblea, en tanto que un Comité de Medidas Colectivas estudiaría la amplificación del sistema.

El año 1950 representa pues un importante desplazamiento del centro de gravedad de las Naciones Unidas y la Asamblea asumió buena parte de la autoridad que en el concepto de sus organizadores, deberían corres-

(1) Ya Aristóteles sostuvo que en todo Gobierno aún para el Gobierno del Mundo, debe existir una Asamblea deliberante para los asuntos de interés público

(2) Como forum se ha usado y abusado en ella de la propaganda. Una señora le preguntaba al delegado norteamericano Warren Austin, durante una de las sesio. nes de la Asamblea, cómo podía resistir tanta palabrería. "Señora, le repuso el Embajador Austin, es mejor que los diplomáticos tengamos úlceras y nó que se mate a los jóvenes". 
ponder al Consejo de Seguridad. (1) Ha sido el más dramático desarrollo funcional de la Carta.

La Carta abrió un nuevo campo: el estatuto y tratamiento de los seres humanos. Las Naciones Unidas se han comprometido a promover el respeto universal y la observancia de los derechos humanos y las libertades fundamentales para todos los pueblos sin distinción de raza, sexo, lengua o religión. La inclusión de estas disposiciones en San Francisco, en 1945, fue una consecuencia de las atrocidades cometidas por los nazis. Pero es también reflejo de una nueva conciencia internacional de los ideales occidentales y liberales. El triunfo de la civilización occidental no solo consiste en conquistas materiales y mecónicas. Los ideales proclamados en la American Declaration of Independence, en el Bili of Rights en el Common Law inglés y en la Déclaration des Droits de l'Homme de la revolu-. ción Francesa hơn hecho su comino $\mathrm{y}$ hoy son la aspiración de todos los pueblos del mundo y se ha concretado en la Declaración Universtal de los. Derechos Humanos, hecha por las Naciones Unidas en 1948.

\section{EL CONSEJO DE SEGURIDAD.-EL VETO}

El Consejo de Seguridad, que funciona permanentemente en la sede general, "será organizado de modo que pueda funcionar continuadamente" (art. 28). Se compone de once miembros. Cinco países -China, Estados Unidos, Francia, Inglaterra y Rusia- son miembros permanentes. Los otros seis miembros rotativos son elegidos por la Asamblea, por un período de dos años y pueden ser reelegidos. Esos miembros puramente formales son: en Ia actualidad (1958):

$\begin{array}{ll}\text { Canadá } & \text { Iapón } \\ \text { Colombia } & \text { Iraq } \\ \text { Panamá } & \text { Suecia }\end{array}$

Las funciones principales del Consejo son mantener la paz y la seguridad internacionales, que es su responsabilidad primaria y fundamental; investigar toda controversia o situación que pueda conducir a un conflicto internacional $Y$ recomendar los medios apropiados para solucionar-

(1) Churchill, uno de los Padres de las Naciones Unidas, ha dicho que la estructura de la Organización ha cambiado grandemente, según fue ideada por sus arquitectos, $Y$ señala que las diferencias entre las Grandes Potencias ha determinado un aumento en la responsabilidad de la Asamblea, lo que se ha intensificado por el aumento de nuevos Miembros. Con un nostálgico criterio imperialista, (conforme las elecciones realizadas en octubre último, Argentina ha sido elegida para reemplazar a Colombia, Túnez a Iraq, el gran estadista inglés expresa: "Nosotros queremos bien a todas las Naciones y hemos creado muchas de ellas $y$ hecho lo mejor para garantizar su integridad $y$ prosperidad. Pero es anómalo que el voto o el prejuicio de una pequeña nación pueda afectar los acontecimientos que interesan a poblaciones que, muchas veces, exede el número de aquellas". 
la; las cuestiones del desarme y control de armamentos; determinar la existencia de una amenaza contra la paz o de un acto de agresión y recomendar las medidas que deben tomarse al respecto; instar a los Estados Miembros a que apliquen sanciones económicas y tomen medidas que no impliquen el uso de la fuerza armada para evitar o suspender la agresión: aplicar medidas militares contra un agresor; recomendar la admisión de nuevos miembros, llenadas las condiciones que exige la Carta, -es decir, que sean Estados amantes de la paz, que acepten y puedan cumplir las obligaciones que impone la Carta de las Naciones Unidas (art. $4^{\circ}$ ) y las condiciones que deben reunir los Estados para adherirse al Estatuto de la Corte Internacional de Justicia-, ejercer las funciones de supervigilancia de la administración fiduciaria en las zonas estratégicas (1); proponer el Secretario General a la Asamblea y elegir, de acuerdo con ella, a los jueces de la Corte Internacional de La Haya.

El Consejo de Seguridad actúa en nombre de las Naciones Unidas y en consecuencia, sus componentes se comprometen a cumplir sus decisiones y a poner a su disposición, cuando sea necesario, fuerzas armadas y la ayuda conveniente para el mantenimiento de la paz y de la seguridad internacionales en unia zona determinada.

Las decisiones del Consejo de Seguridad sobre cualquier asunto, salvo en las del procedimiento para las que se necesita una mayoría simple de siete votos, debe tomarse por el voto afirmativo de siete de sus miembros comprendidos los cinco miembros permanentes. En todo asunto en que uno de los Estados que es parte de la controversia, es también miembro del Consejo, debe abstenerse de votar. En cualquier materia que no sea simplemente procesal, si uno de los miembros permanentes vota negativamente, no hay decisión. Es el llamado derecho del veto.

Se ha dicho que el Consejo, que funciona permanentemente, es el órgano ejecutivo de las Naciones Unidas.

John Foster Dulles, actual Secretario de Estado de los Estados Unidos, observaba hace algunos años que la posibilidad para las Naciones Unidas de ser poderosa dependía sobre todo de la Asamblea General. Ei rol del Consejo de Seguridad es predominantemente negativo: mantener la paz y la seguridad, detener la agresión. En cambio corresponde a la Asamblea promover la cooperación internacional, las libertades fundamentales y los derechos humanos, ejercer la administración sobre los territorios bajo tutela y promover mejores standards de vida.

La función del Consejo es eminentemente política: mantener la por y la seguridad internacionales -world's peacemaking- que las ejerce con autoridad propia no está sujeto al control de la Asamblea ni ésta puede impartirle instrucciones.

Las Grandes Potencias ofrecieron autolimitarse en el uso del veto durante la Conferencia de San Francisco. El veto representaba además la

(1) Las únicas zonas estratégicas son las islas del Pacífico, antiguos mandatos japoneses, (islas Carolinas, Marshalls Y Marianas) administradas en la actualidad por los Estados Unidos. 
legalización temporal de la Alianza durante la Segunda Guerra Mundial en una asociación permanente de los tiempos de paz, en que los vencedores actuarían de concierto y el reconocimiento de la verdad notoria que la nueva organización mundial necesitaba el acuerdo de los Cinco Grandes para funcionar con eficiencia. Pero, desde entonces, el mundo ha estado dividido en dos grandes bloques opuestos. El Consejo muchas veces ha quedado paralizado y no ha podido actuar - hasta se han producido vetos de los cuales no todos fueron de Rusia - en tanto que la Asamblea ho ampliado y afirmado su acción, particularmente por la Resolución "Unión for Peace" pues como hemos visto (1) implicó un cambio radical desplazóndose el centro de gravedad del Consejo a la Asamblea. Así, el asunto de Grecia y los guerrilleros comunistas fue removido de la Agenda del Consejo; y entonces la Asamblea de 1947 lo consideró en su Orden del Día, designando un Comité Especial para los Balkanes; y lo mismo en el asunto de Corea, en que nombró otra Comisión que se hallaba en la región cuando estalla. ron las hostilidades y que informó inmediatamente de lo que ocurría.

Si el Consejo queda paralizado tratándose de un acto de agresión, la Asamblea puede reunirse en un plazo de veinticuatro horas. Es una forma de soslayar el veto en caso de agresión pues la Asamblea puede tomar una decisión por mayoría de dos tercios, olvidándose la exigencia del voto concurrente de todos los miembros permanentes del Consejo do Seguridad (2).

\section{El Veto en el Consejo de Seguridad}

En la Liga de las Naciones todas las decisiones, ya fueran del Consejo o de la Asamblea, debían tomarse por unanimidad. La abstención no se entendía como voto negativo sino como expresión de aceptar la decisión pero sin su específica aprobación. La Liga solía aprobar meras recomendaciones por simple mayoría. Otra fórmula era aproblar una cuestion por mayoría en los Comités y no llevarla al plenario hasta que se estuviera seguro de la unanimidad.

Al planearse las Naciones Unidas, las Estados Unidos consideraron que el Consejo de Seguridad no debería tener poder sobre ellos sin su

(1) La Unión Soviética ha objetado esta resolución sosteniendo que es violatoria de la Carta, al destruir el principio de la responsabilidad conjunta de las Grandes Potencias y deprimiendo al Consejo de Seguridad de sus legítimos poderes, lo que es una oposición explicable porque la resolución Unión for Peace ha permitido ampliar el órea de decisiones que pueden tomarse sin el consentimiento del Consejo de Seguridad. Pero durante el asunto de las tropas extranjeras en Lúbano invocó esa resolución para pedir la convocatoria inmediata de una Asamblea Extraordinaria.

(2) Se ha dicho que el declinar el Consejo de Seguridad como órgano principal del mantenimiento de la paz, y el surgimiento de la Asamblea General es incuestionablemente el desarrollo constifucional mós significativo que se ha producido en las Naciones Unidas. "Véase, U. N., the first ton Years", por Clark M. Eichelberger. 
consentimiento y demandaron el veto. La Rusia Soviética pensando en la organización sobre todo como un órgano de seguridad, destinado a proteger sus posiciones adquiridas, abogó también por el principio de la unanimidad. China y Gran Bretaña fueron en Dumbarton Oaks menos insistentes en el veto. Entonces no se llegó a ningún acuerdo. Sólo en Yalta, donde se decidió también la convocatoria de la Conferencia de San Francisco, se acordó la fórmula del veto que después se incorporó a la Carta.

El problema del veto ha sido el más difícil y complejo de la Organización como funcionamiento y como política. En el Consejo se han producido 89 vetos, de los cuales 85 han sido de Rusia, 4 de Francia, 2 de Gran Bretaña, 1 de China y ninguno de Estados Unidos, (1) abuso que, en muchos casos, solo ha conducido a la futilidad o a la frustración.

Rusia ha abusado del veto, en forma extensiva y contrariando la promesa de aplicarlo lealmente, (el último $\mathrm{N}^{\circ} 83$ lo h'a emitido en mayo último sobre la propuesta norteamericana de Inspección sobre el Artico), solo cuando viera comprometida su seguridad y que no se entrentaría al juicio moral del mundo. Ha sido la consecuencia de una política soviética de post-guerra agresiva, no cooperativa y recelosa o sea una política internacional fijada por sus propios términos.

En San Franciso, las Pequeñas y Medianas Potencias, deseosas de establecer una efectiva Organización y conscientes de que ésta debería tener poderes coercitivos en interés de la paz, fueron opuestas a que los Grom. des estuvieran exceptuados de este poder de coerción. Pero en la tenaz batalla que libraron intentaron, sin éxito, modificar la fórmula de Yalta.

Lo único que se logró fue una Declaración de las Cuatro Potencias Organizadoras de la Conferencia sobre el Veto en el Consejo de Seguridad, que en esencia, dice que los Poderes que pidieron el veto en Yalta lo continúan necesitando y recordando que cualquier situación en que las Naciones Unidas intentaran ejercer una acción coercitiv'a contra un Grande, solo podía resolverse en otra Guerra Mundial o en la bancarrota de las Naciones Unidas. Aceptaron tambión que cuando una nación, grande o pequeña, fuera parte de una controversia, se abstendría de votar. (Art. 27 de la Carta).

Además, en San Francisco, se juzgó que el problema primordial en los años a venir sería el control de Alemania y el Japón y no la rivalidad entre las Potencias vencedoras. En cambio el gran problema de la última década, ha sido la política expansiva y conquistadora que realiza la Rusia Soviética en tanto que, contra lo que se preveía, los Estados Unidos han ayudado al resurgimiento industrial y económico de Alemania y seguido una política generosa con el Japón el que fué elegido en 1958 para el Consejo de Seguridad con la decidida ayuda de los Estados Unidos. Los primeros problemas que tuvieron que afrontar las Naciones Unidas no fueron con el

(1) Sumados individualmente aparecen 92 vetos, pero se debe a que cuando el asunto del Gobierno español de Franco, Rusia y Francia votaron negativamente; y cuando el debate del Canal de Suéz, Inglaterra y Francia vetaron en dos oportunidades, al mismo tiempo, los proyectos de resolución. 
Japón y Alemania sino la presencia rusa en Irán, los guerrilleros en Grecia alentados por los países comunistas satélites y favorecidos por el debilitamien. to de la influencia y poder ingleses y los reclamos de Líbano y Siria contra la presencia de tropas extranjeras en su territorio y la continua división de estados soberanos como Alemania, Vietnam y Corea y la opresiva política de la Unión Soviética, respecto a los Estados de la Europa Oriental.

En el Consejo de Seguridad, las Potencias Occidentales han contado con mayorías homogéneas $y$ solo en pocos casos, como en la crisis del Canal de Suez, usaron del veto. Los rusos se quejan de lo que llaman esa "mayoría mecánica".

Rusia y Occidente marcharon juntos durante la guerra pero este "Working-agreement" se quebró apenas terminadas las hostilidades, lo que se puso inmediatamente de relieve durante el bloqueo ruso de Berlín. Los rusos, sintiéndose fuertes, han realizado una propia política de expansión, primero en Europa Oriental, transformando en satélites, antiguas naciones como Polonia, Bulgaria, Rumanía, Albania, Checoeslovaquia y durante algún tiempo Yugoeslavia (hasta que el Mariscal Tito decidió seguir su línea independiente de "socialismo nacionai"); la sangrienta represión en Hungría y ahora su acción perturbadora en el Medio Oriente, en la zona de los países árabes (Egipto, Siria y Líbano). Inglaterra salió de la guerra notoriamente debilitada $y$ ha tenido que moverse a la defensiva; Francia amarrada con conflictos políticos internos, con la liquidación del colonialismo y con el grave problema de Argelia; la China nacionalista desplazada del Continente, en poder de los comunistas y encerrada en Formosa; y los Estados Unidos teniendo que multiplicarse para mantener su situación de leader en el mundo de las naciones libres y llenar los vacíos dejados por las otras Potencias.

El Consejo de Seguridad ha establecido la doctrina que las abstenciones o ausencias no impiden una resolución afirmativa. El veto debe expresarse mediante un voto negativo. Así en los casos de la queja inglesa contra la colocación de minas en el Canal de Corfú por Albania, en la creación del Comité de Buenos Oficios de Indonesia y la Comisión de Mediación en Cachemira, las abstenciones de los miembros permanentes no impedieron que se consideraban aprobadas las resoluciones. Ásimismo el acuerdo que se tomó en el caso de Corea, en junio de 1950, en ausencia de la Unión Soviética (que desde hacía meses, no concurría al Consejo en protesta por la presencia del Delegado de la China Nacionalista en vez de ser uno de la China Comunista) se consideró que la ausencia no era veto.

Existe una fuerte tendencia para limitar el ejercicio del veto a los asuntos comprendidos en el Capítulo VII, de la Carta, relacionado con los actos de agresión o rompimiento de la paz, que pueden acarrear la aplicación de sanciones y medidas coercitivas; pero no cuando se trata del Capítulo VI, arreglo pacífico de las controversias o admisión de nuevos miembros, lo que parece más conforme con el espíritu que inspiró el veto y las exigencias del normal funcionamiento del Consejo de Seguridad. 


\section{El Consejo Económico y Social. - La Asistencia Técnica}

El Consejo Económico y Social se compone de dieciocho miembros, elegidos por tercios cada tres años. Las Grandes Potencias son sucesivamente reelegidas así como los países llaves en el desarrollo industrial. Sus funciones se refieren al progreso económico y bienestar social de los pueblos miembros de la Organización.

El Consejo ha crecido con una compleja organización estructural y con una gran variedad de instituciones que pueden ser comisiones funcionales o regionales, comités ad-hoc y cuerpos especiales. Además existen tres comisiones regionales económicas, una para Europa, otra para Asia y Extremo Oriente y la tercera es la Comisión Económica para América Latina (CEPAL), cuya sede regional es la ciudad de Santiago de Chile y que ha prestado müy útiles servicios para planear el desarrollo económico Iatinoamericano, estudios económicos, asistencia e información. La Asamblea de 1958 ha establecido otra Comisión Económica para Africa. En muchos casos el Consejo es responsable ante la Asamblea General; en otros actúa por su propia iniciativa.

$\mathrm{Al}$ estructurarse las Naciones Unidas se reconoció que las condiciones sociales y económicas de los pueblos tenían una relación directa con la paz internacional. Miseria y descontento implican frustraciones y tensiones que pueden destrozar el orden, la estabilidad y la seguridad internacionales, representando un campo abonado para los extremismos y doctrinas agresivas y las dictaduras militaristas. La paz sólo puede mantenerse por el empleo de un ejército que mantenga el statu quo, situación que solo puede ser transitoria y explosiva. Por eso el mejoramiento de las condiciones sociales y económicas alivia la tensión internacional y favorece la paz. Al perseguir este goal de desarrollo económico, la mejor utilización de los recursos es de básica importancia. El artículo 55 de la Carta dispone que las Naciones Unidas facilitarón la creación de condiciones de estabilidad y bienestar que son necesarias para las relaciones pacíficas y amistosas entre las naciones, basados en el respeto al principio de la igualdad de derechos y de la libre determinación de los pueblos, y que la Organización promoverá:

a) Niveles de vida más elevados, trabajo permanente para todos $y$ condiciones de progreso y desarrollo económico y social; b) La solución de los problemas internacionales de carácter económico, social y sanitario $y$ de otros problemas conexos; y la cooperación internacional en el orden cultural y educativo; y c) el respeto universal de los derechos humanos y a las libertades fundamentales de todos los hombres, sin hacer distinción por motivos de raza, sexo, idioma o religión y luchará por la efectividad en el tales derechos y libertades. Con ese objeto se ha creado una Comisión de goce de Derechos Humanos para proteger la libertad y la dignidad del hombre, lo que, por primera vez, se hace en el plano internacional. Acaba de establecer un Fondo de Desarrollo Económico para impulsar proyectos de progreso económico y desarrollo estructural de los países menos desarro. llados con un capital, inicial de 100 millones de dólares. 
Cuando se haga la historia completa de las Naciones Unidas su obra será juzgada por el cumplimiento de la mejora en los standards de nutrición y salud $y$ en el planeamiento de un mundo más libre, más próspero, mejor educado e integrado para promover una vida mejor y más completa para todos los pueblos en un mundo pacífico. Porque la necesidad de un incremento social y económico de las naciones subdesarrolladas es, ha dicho el Secretario General Hammarskjold, el mayor desafío que afronta la Organización.

\section{La Liquidorción del Colonialismo}

Estamos viviendo el final del Colonialismo, la gran aventura que comenzó en el siglo XVI y culminó en el siglo XIX.

Una cuarta parte de la población mundial, 650 millones de seres, ha ganado su independencia desde la conclusión de la Segunda Guerra Mundial. India, Birmania, Ceilán, Pakistán, Indonesia, Sudán, Indochina, Maruecos, Túnez y últimamente Ghana, Malaya y Guinea, las más jóvenes de todas, son hoy en día naciones libres y soberanas. Otros doscientos millones de seres, están en proceso o luchando para ganarse esa independencia como Argelia, Somalia, Nigeria, Singapore, Chipre y la Isla de Malta (1). Esa revolución anticolonial ha sido facilitada por la debilidad de las naciones europeas, a raíz de la Segunda Guerra Mundial, la intensificación del nacionalismo y un sentimiento generalizado de justicia social, auque como en el caso de Indonesia, se preguntan si esas nuevas naciones no han advenido a la vida independiente no del todo maduras.

Esa independencia ha sido estimulada y canalizada a través de las Naciones Unidas como lo ha sido en los casos de Indonesia, Túnez, Marrue$\cos$ y Ghana. La Organización no sólo ha facilitado la transformación de antiguas colonias en Estados Libres sino que ha permitido soluciones juridicas que, de otro modo, habría estall,ado en la violencia $y$ en la lucha crmada. (1) Asimismo una vez independientes las ayudas a convivir dentro de la gran familia de naciones. Las nuevas naciones son naturaimente las más vehementes defensoras de las que todavía no lo son.

Esta lucha por la independencia ofrece ulteriores facetas. La revolución contra el imperialismo político se prosigue en la revolución contra el impericlismo económico y contra el hambre, lucha que, por cierto, es mucho más difícil y dura. Las naciones pobres y atrasadas saben que hay otras que no lo son $Y$ desean progresar, explotar sus riquezas $y$ elevar su standard de vida. La mitad de los hombres del mundo no saben leer ni escribir ni pueden cubrir sus necesidades elementales: comida $y$ techo. Las Naciones Uni-

(1) 'Sin la absorbente capacidad de las Naciones Unidas, y de ser un forum para que las naciones coloniales expusieran sus quejas, el mundo puede ser que hubiera explo tado. La sabiduría con que las Naciones Unidas ayudan a las potencias coloniales a dar libertad 7 gobierno propio a los que no lo tienen, tiene mucho que ver con la paz deI mundo". Eichelberger ob. cit. 
das han iniciado un novedoso y fecundo programa a través de la Asistencia Técnica: ayudar a los pueblos atrasados a que se ayuden a sí mismos. Naciones ricas y pobres, industrializadas y subdesarrolladas, trabajan pues en una empresa común de gran responsabilidad. Hay países como la India, el Egipto y otros pueblos de Asia, de Arabia o de Latinaamérica que están orgullosos de su cultura y de su historia pero que son muy pobres, con un bajísimo standard de vida, $y$ tienen además un alto índice de crecimiento demográfico. Este aumento de población, su transformación política, su naciente industrialismo y su celoso nacionalismo tendrán una influencia decisiva en el futuro internacional. El Delegado del Líbano, Presidente de la Asamblea de 1958, Carios Malik, dijo una verdad simple y profunda cuando afiirmó que, en la medida que el Consejo Económico y Social promueva soluciones para los pueblos subdesarrollados, los problemas que debe enfocar el Consejo de Seguridad declinarán proporcionalmente.

La Asistencia Técnica se ha establecido para suministrar $\alpha$ los países subdesarrollados, conocimentos técnicos para el desarrollo de sus economías $y$ funcionarios experimentados internacionales, capacitados en diversos problemas técnicos y en movilizar información y desarrollar nuevos recursos de esos países. Sin lo que en inglés se llama "Know how" saber cómo un país no podrá explotar sus riquezas.

La Asistencia Técnica es la "ayuda a los pueblos a ayudarse a sí mismos" Y trabajan en ellas 1,800 expertos que provienen de 65 países. Son los modernos misioneros, que, al mismo tiempo que enseñan a los pueblos atrasados las ventajas de la tecnología moderna, les facilitan vivir en libertiad, enviándoles expertos y trazando planes pilotos para su desarrollo y el cabal aprovechamiento de sus riquezas.

Inglaterra ha dado un magnífico ejemplo. Con su sentido realista que raras veces lo pierde -salvo en la aventura del Canal de Suez- el Imperio Británico ha desarrollado desde 1945 una política que podríamos llamar de "constructiva abdicación". O sea transformar lo inevitable en libremente aceptado.

Ha otorgado la independencia a India, Pakistán, Ceilán, Birmaniaque es el único que no forma parte del Commonwealth- Ghana y Malaya y reune a sus Primeros Ministros, como iguales, en un plano de absoluta igualdad en conferencias periódicas anuales.

\section{El Conseio de Tutela}

El Consejo de Tutela tiene a su cargo inmediáto la supervisión de los territorios bajo mandato y debe reportar y recibir instrucciones de la Asam. blea General, tratándose de los teritorios no estratégicos y del Consejo de Seguridad en el caso de áreas estratégicas.

El Consejo está constituído de manera diferente de la Comisión de Mandatos de la extinguida Liga de Naciones. En ésta se trataba de expertos designados por la institución y no representaban a sus gobiernos. En las Naciones Unidas son representantes de sus gobierno, tienen un carácter político y gozan de mayor autoridad aunque en la designación de esos delegados se prefiere a personas calificadas en asuntos coloniales. 
El Consejo de Tutela considerará los informes que le presenten los Estados administradores, escuchará y examinará las peticiones que le formulen los representantes de los habitantes de los territorios bajo mandato y hará visitas periódicas a dichos territorios.

El Consejo de Tutela o de Adminisiración Fiduciaria, como también se le llama en español (1) está integrado pri trece miembros que se descomponen así: los miembros de las Naciones Unidas que administran territorios bajo fideicomiso (Australia, Bélgica, Estados Unidos, Francia, Italia e Inglaterra), los miembros ex-oficio por ser miembros permanentes del Consejo de Seguridad cque no administran tales territorios (China y Rusia) y por otros tantos miembros cuanto sean necesarios para asegurar que el número total de miembros del Consejo se divida por igual entre los miembros administradores. Estos últimos son elegidos por un período de tres años y pueden ser reelegidos y su número es ahora de cinco (2). Sus funciones principales son: fornular los pianes de trabajo para el progreso político, social, económico y educativo de dichos territorios, considerar los informos que presentan las autoridades administradoras, ayudar a desenvolver sus propias instituciones, examinar las peticiones que hacen sus habitantes, estimular el desarrollo de los derechos humanos y facilitarles la independencia y el gobierno propio. $Y$ en realidad las funciones que viene cumpliendo el Consejo de Tutela es mayor que el que pudo anticiparse al establecerse la Carta de San Francisco.

Los territorios bajo fideicomiso son:

Naurú por Australia, (en nombre de Australia, Nueva Zelandia e Inglaterra);

Nueva Guinea por Australia;

Ruandia Urundi por Bélgica;

Togo y Camerún por Francia;

Somalía por Italia;

Samoa Occidental por Nueva Zelandia;

Camerún, Togo y Tanganika por Inglaterra;

Islas del Pacífico, (Marshall, Marianas y Carolinas por Estados

Unidos. Se trata de un antiguo mandato japonés y se le considera como una zona estratégica).

Como se ve, se ha procurado una composición balanceada entre los Estados administradores y los no administradores, pero dándose cabida siempre a las Grandes Potencias, miembros permanentes del Consejo de Seguridad y que tienen evidente interés en los problemas coloniales y en su futuro.

(1) La expresión inglesa "trusteeship" se puede traducir en ambas formas, pero en la versión española de la Carta hecha por la Secretaría de las Naciones Unidas, se emplea el término "Administración Fiduciaria".

(2) En el Consejo hay cinco Representanfes de los Estados Administradores contra seis de los no Administradores. 
Los territorios bajo tutela que son áreas estratégicas - el único cuso es el de las antiguas colonias alemanas del Pacífico, islas que fueron confiadas en mandato al Japón al terminar la primera guerra mundial y çue ahora las administra los Estados Unidos- están bajo la dependencia directa del Consejo de Seguridad; los demás territorios en fideicomiso dependen, en última instancia, de la Asamblea General. La diferencia estrib.a en que en el primer caso, los Estados Unidos podrían vetar cualquier decisión con la que no estuvieran de acuerdo. En qambio, como la decisión final sobre los territorios no estratégicos (régimen de administración, posikilidad de toncrse indepenciente, cambio de mandatario) corresponde a la Asamblea iaquí no funciona el veto, el que tampoco existe en el Consejo. de Tutela.

La Carta incluye un Capítulo, el XI, conteniendo una Declaración Especial sobre los territorios no autónomos. Los Estados que tienen a su cargo esos territorios se comprometen a promover el bienestar de los pobliadores, a asegurar su progreso político, social, ecnómico y educacional, su justo tratamiento, a protegerlos contra abusos, $\alpha$ favorecer su autonomía y asistirlos en el progresivo desarrollo de sus instituciones políticas.

El régimen de tutela cubre actualmente diez territorios: seis en Africa bajo la administración de Inglaterra, Francia y Bélgica; Somalía bajo la administración italiana (aunque su independencia se ha fijado para 1960); dos en el Pacífico Occidental, bajo la administración de Australia y Nueva Zelandia y el territorio de las islas del Pacífico (Marianas, Marshall y Caro linas), bajo la administración de Estados Unidos. Cada uno de esos territo. rios ha sido objeto de un acuerdo de tutela entre las Naciones Unidas y el Estado administrador.

La Carta ha creado una maquinaria internacional especial para supervigilar la administración de los territorios, cuestionarios, informes, peticiones y la visita anual de una Comisión de las Naciones Unidas. (1)

Las Naciones Unidas no son ni intentan ser un gobierno del mundo; pero sí en alguna forma lo son y cumplen esas funciones es en los territorios bajo tutela que no gobiernan directamente pero cuya administración supervigilan. •

Una resolución de la Asamblea, en 1949, dispuso que la bandera de las Naciones Unidas se ize en los territorios bajo tutela, al lado de la bandera del país administrador, simbolizando los ideales y aspiraciones proclamados en la Carta y recordando que esos territorios pertenecen más a los que viven en ellos que $\alpha$ los que los administran.

(1) El acuerdo o tratado suscrito en cada caso, obliga a la autoridad administrativa a administrar el territorio dentro de los principios básicos conteridos en la Carta, garantizar la paz, orden $\mathrm{Y}$ buen gobierno del territorio, desarrollar sus instituciones políticas $\mathrm{Y}$ dar a los habitantes una participación en el gobierno; desarrollar sus instituciones, asegurar la libertad de religión, culto, prensa, reunión y fetición; protegar los derechos de los nativos sobre la tierra; asegurar igual tratamiento a todos los Miembros de las Naciones Unidas $Y$ a sus nacionales. Dentro de estas obligaciones, el Administrador tiene plenos poderes de legislación, administración y jurisdicción en el territorio, incluyendo el derecho de establecer bases militares y la defensa local. 


\section{ANTECEDENTES DEL REGIMEN DE TUTELA}

Al concluir la primera Guerra Mundial, las colonias alemanas y antiguos territorios del Imperio turco, en vez de ser anexadas a las potencias vencedoras se pusieron, principalmente por la insistencia del Presidente Wilson ("el bienestar y desarrollo de esos pueblos implicaba un sagrado encargo de la civilización"), bajo la supervisión de la Liga de las Naciones, en cuyo nombre serían administradas por algunos países que pertenecían a la organización y que actuarían como "Potencias Mandatarias". A esos territorios se les llamó "territorios bajo mandato" y eran de tres clases: clase $\mathrm{A}$ como los mandatos que ejercían Francia sobre Líbano y Siria y la Gran Bretaña sobre Iraq, Palestina y Transjordania; clase B como los de Bélgica sobre Ruanda-Urundi; Gran Bretaña y Francia sobre Tanganika y una parte del Camerún; y clase C como los de la Unión Sudafricana sobre Suroeste del Africa, el Japón sobre las islas del Pacífico, Nueva Zelandia sobre Samoa Occidental, Australia sobre Nueva Guinea y Su Majestad Británica -mandato ejercido según acuerdo por Australia- sobre Nauru. Una Comisión Permanente de Mandatos, compuesta de expertos designados por la Liga, recibía los informes anuales y ejercía una especie de supervisión sobre los actos de la Potencia mandataria.

Al cesar la Liga y crearse las Naciones Unidas se habían producido en el mundo, nuevas condiciones que afectaban a los pueblos bajo mandato. Algunos de ellos ya habían alcanzado su independencia como el Iraq en 1932. Siria y Líbono en 1945 y otros estaban en trance de lograrlo como Jordania y Palestina, es decir todos los antiguos mandatos de la clase A. EI nacionalismo había crecido en esos territorios estimulado por el ejemplo de otros paises, por las promesas de selfgovernment hechas durante la guerra, por la prédica de otras naciones como el panarabismo nacionalista o Hindú y por la propaganda antieuropea y antiblanca durante la ocupación japonesa.

Occidente compartía esa simpatía por la independencia de los pueblos de Asia y más tarde de Africa. Los Dominios Britónicos se habían tornado independientes después de la aprobación del Estatuto de Westminster de 1931. Los Estados Unidos habían reconocido la Independencia de Filipinas, formalmente proclamada en 1946, y que ya era un nuevo miembro de las Naciones Unidas, A. Hawai, Puerto Rico, e Islas Vírgenes, los Estados Unidos les han dado casi completa autonomía. En general se tenía la convicción que se estaba liquidando el colonialismo, como lo probaban las fáciles conquistas japonesas de 1941 y 1942. Era difícil que Indonesia e Indochina volvieran a ser incorporadas al status de la preguerra.

En 1943 el Presidente Roosevelt pensaba que debería darse a las potencias mandatarias una especie de "colonial time-table" a tiempo fijo, indicándose la fecha en que cada colonia debería alcanzar su independencia y en el interím, establecer la administración por un sistema internacional de tutela.

Dentro de esos antecedentes la Carta de San Francisco estableció: 1ํ- 
Un Régimen Internacional de Tutela; $2^{\circ-L o s ~ C a p i ́ t u l o s ~ X I I ~ y ~ X I I I ~ d e ~ l a ~ C a r t a ~}$ relativos al Régimen Internacional de Administración Fiduciaria y al Consejo de Tutela, y $3^{\circ}$-Una Declaración relativa a los Territorios No Autónomos (Capítulo XI).

En razón de esta Declaración, los Estados Administradores reconocen el principio según el cual los intereses de los habitantes de esos territorios están por encima de todo, aceptan como un encargo sagrado la obligación de promover en todo lo posible, el bienestar de sus habitantes, asegurar el debido respeto a su cultura $y$ a su adelanto político, económico, social $y$ educativo, a su justo tratamiento y a desarrollar su gobierno propio, a tener en cuenta sus aspiraciones políticas y a trasmitir al Secretario General de las Naciones Unidas las informaciones sobre el desarrollo de esos territorios.

Por razones de seguridad militar, los Estados Unidos insistieron en la necesidad de crear un régimen especial para ciertos mandatos como las antiguas islas colonias japonesas del Pacífico, que habían demostrado ser tan importantes para el Japón en su guerra contra los Estados Unidos y que el Estado Mayor norteamericano consideró que en lo sucesivo deberían permanecer bajo el control militar permanente de este país. En consecuencia, la Carta se refiere a una clase especial de territorios bajo tutela denominada "área estratégica" casos en que el Acuerdo de Tutela está sujeto a la apra bación del Consejo de Seguridad -donde hay derecho de veto por las Potencias que son Miembros Permanentes- y no a la de la Asamblea General. Puede designarse en cualquier momento una área estratégica (art. 82) y sobre ella no tiene derecho ni la Asamblea General ni el Consejo de Tutela, ni pueden interferir los civiles sino el Consejo de Seguridad, cuya única función es aprobar y modificar el Acuerdo de Tutela. La Carta no especifica qué entiende por zona estratégica.

\section{LOS PRIMEROS CATORCE AÑOS DE LAS NACIONES UNIDAS}

La primera década de las Naciones Unidas coincidió con la primera bomba atómica; en la segunda se comienza la aplicación de la energía atómica para fines pacíficos y la conquista del espacio sideral con el lanzamiento de los satélites. En el curso de esos años la Organización se ha desarrolliqdo rápicia y afirmativamente, no obstante que fué creada en. una época cataclismática. Sin la fuerza jurídica y moral que ella encarna, el mundo -quizás no habría sobrevivido $y$ muchas crisis internacionales que han surgido en estos diez años habrían desencadenado una III Guerra Mundial, de no existir las Naciones Unidas, pues los debates y negociaciones realizados bajo su égida han prevenido que se transformen los incidentes y conflictos bélicos en guerra abierta. Con el aumento de sus miembros, las Naciones Unidas reflejon más fielmente que nunca la realidad de la situación mundial, a pesar de que necesariamente el cuadro que presentan los debates y las votaciones en las Naciones Unidas sólo es posible evaluarlo exactamente después de un análisis cuidadoso. Las Naciones Unidas reflejan el renacimiento de Asia, pero no son en modo alguno su causa. El despertor de Africa, y los otros cambios importantes que se están 
realizando en el equilibrio de poderes $y$ en las relaciones entre los pueblos, son también parte de la dinámica de la historia. Ha ayudado la Organización al nacimiento pacífico y ordenado de una media docena de nuevos Estados. Como siempre traen consigo muchos problemas graves de adptación que con toda facilidad pueden servir de ocasión para despertar pasiones, temores $y$ odios que a su vez conduzcan a trastornos violentos $y$ al desastre definitivo de una guerra en esta era atómica. (1) Muchas veces la acción del Consejo de Seguridad ha detenido la agresión, conciliándose puntos de vista contrarios sin renunciar a los principios. Un fracaso de la Organización habría sido una invitación a que se imponga el más fuerte y a vivir en un "law-lessiness world".

Para las naciones occidentales el aspecto de la seguridad es el más importante en la Carta de las Naciones Unidas. Para las de Ásia los de justicia social y desarrollo económico, para los de Africa los relativos a los Derechos Humanos, para los de América Latina la igualdad jurídica y la elevación del standard de vida de las clases más atrasadas. Pero todos se sienten ligados a la totalidad de las obligaciones y deberes de la Carta, aplican las prácticas parlamentarias de la Ásamblea y participan en sus actividades técnicas, unidas todas las Naciones: viejas y recién nacidas, desarrolladas y atrasadas, en el común propósito de mantener la paz y evitar una nueva guerra que, con los terribles armamentos nucleares y los proyectiles dirigidos, podría acabar con la especie humana.

Pero el acontecimiento más importante y revolucionario de la primera década de Naciones Unidas ha sido la insurgencia contra el colonialismo $y$ el advenimiento de doce naciones libres con un total de 650 millones de almas, política que la distingue netamente de la antigua Liga de Naciones.

Las Naciones Unidas no han producido esa revolución. Ella estaba en el ambiente del mundo y la esperanza de esos pueblos, pero la Carta de San Francisco recogió ese ambiente y esa esperanza al reconocer el derecho de los pueblos de ser libres $y$ al ejercer las atribuciones que se le dió para cooperar al libre gobierno de esos pueblos. Y la transformación de esas antiguas colonias en Estados Soberanos debe ser lo más ordenada posible a fin de que no se produzcan vacios ni sufran en su desarrollo, los nuevos Estados, ni se amenace la estabilidad del mundo.

Dar el propio gobierno o independencia a los 150 millones de hombres que aún no lo tienen es la tarea de la próxima década de las Naciones Unidas. Su cumplimiento presenta dificultades. Pero, si esa aspiración se realiza en una forma ordenada, como en Ghana, o con tumultuosas explosiones como en otras colonias, depende como las naciones apliquen los principios de la Carta. Y una vez libres, ellos deben ingresar inmediatamente $\alpha$ la Organización de las Naciones Unidas como han sido los casos de Ghana y Malaya, porque implica una participación $y$ una responsabilidad en la gran familia de Naciones y porque en esa forma se afirma su personalidad internacional.

(1) Introducción a la Memoria Anual del Secretario General de las Naciones Unidas, New York, 1957. 
Las Naciones Unidas han presentado una unidad moral de los pueblos que ha superado las transformaciones casi revolucionarias de los últimos diez años. Sin esta unidad moral quizás el mundo habría sido destruído. La institución creada en San Francisco queda intacta y su vida no ha sido tan precaria como lo fué la de Liga de las Naciones o las Repúblicas Francesa o Norteamericana, en los doce primeros años de existencia. Ha tenido éxito por una serie de pasos, "grow by growing" o sea un crecimiento funcional.

Una hora después que Trigve Lie asumió su puesto de Secretario General de las Naciones Unidas en marzo de 1946, el Embajador de Irán presentaba su queja con el reclamo de su país por la presencia de tropas rusas en su territorio.

Desde entonces las Naciones Unidas han vivido en constante crisisIrón, Grecia, Indonesia, Palestina, Bloqueo de Berlín, Corea, China, Desarme, Energía Atómica, Admisión de Nuevos Miembros, Checoeslovaquia, Canal de Suéz, Hungría, Argelia, Desarme, Espacio Sideral, Líbano y Jordania. Aceleró la independencia de Siria, Líbano, Indonesia e Israel, y redujo la tensión durante el bloqueo de Berlín proveyendo un tercer camino frente a alternativas de rendición humillante o de violento desafío. Ha creado la Fuerza de Emergencia para patrullar y mantener la paz en la frontera entre Israel y Egipto y asimismo, cuando la crisis de Líbano, ha establecido un grupo de observadores para evitar la infiltración de elementos extraños. Subsiste y actúa en el medio de la crisis y se viene afirmando. Otra razón de la existencia de las Naciones Unidas es el crecimiento y desarrollo de la técnica moderna, dentro de lo que llamaríamos los fundamentos económicos de la paz y los fundamentos de la libertad humana. El progreso económico. las tarifas aduaneras, la asistencia técnica, los correos y comunicaciones, el control de los narcỏticos, los derechos humanos, la protección de la salud, de la educación y de la cultura requieren una atención y un sistema internacionales a los que se agregan los problemas del desarme, los proyectiles dirigidos, las armas nucleares y la amenaza potencial de la parafernalia de las destrucciones en masa.

Pero, por desgracia, si la cooperación internacional ha devenido necesaria no implica que sea más fácil. Subsisten los odios históricos, los antagonismos tradicionales, las ideologías tajantes y el mundo dividido por diferencias históricas. Continúa la "guerra fría". La cooperación internacio nal es pues difícil y dura pero va haciendo su camino. Los problemas siguen existiendo, es un legado de la Historia y sería irracional que no existieran. Las Naciones Unidas no pueden impedir que surjan esos problemas, pero tienen la maquinaria para afrontarlos y los principios conforme a los cuales deben resolverse.

La comunidad de las Naciones Unidas o familia de naciones representa universalidad, continuidad y comprensión.

La universalidad no solo es la universalidad en la Organización, alcanzada ahora con 81 Estados Miembros, (solo están ausentes Suiza por propia decisión; Alemania, Vietnam y Corea por estar divididas y China comunista por su condición de agresor), sino que los asuntos que trata 
interesan no sólo a las Grandes Potencias sino a todos los pueblos, grandes y pequeños. Claro que no todos ellos afectan a todas las Naciones en el mismo grado. El regionalismo tiene un sitio dentro de la Organización y las Grandes Potencias ejercen una influencia natural.

La continuidad en el esfuerzo es otra de las características de las Naciones Unidas, una organización que trabaja todo el tiempo. Pese $\alpha$ divisiones, disputas y antagonismos, las naciones han adquirido el hábito de trabajar juntas -los Jefes de Gobierno y Ministros en los grandes meetings, los diplomáticos $\mathrm{y}$ delegados en las reuniones periódicas, los técnicos en las conferencias especializadas-. Y si el mundo se mueve hacia una verdadera comunidad es sólo a través de una organización como las Naciones Unidas.

Hay que advertir que en las Naciones Unidas es casi el único sitio donde la Unión Soviética mantiene continuo contacto con el resto del mundo y el "meeting-place" en que, pese $\alpha$ ataques $y$ cargos, thata $y$ discute con las Potencias Occidentales y demás naciones no comunistas, sobre los problemas políticos. Es el "trait d' union", el único puente de tránsito.

\section{LA OBRA DE LAS NACIONES UNIDAS}

Los Estados Miembros de las Naciones Unidas no están vinculados solamente por la Carta de la Organización que han firmado -el concepto de pacta sunt servanda - sino por una razón natural, porque están llamados a convivir y a cooperar en una sociedad internacional que la vida impone en tanto que el desarrollo de la técnica y de las comunicaciones aproxima cada día más a los pueblos. $O$ sea una cooperación fundada en un orden jurídico internacional, superior a la propia soberanía nacional que subsiste y se respeta dentro de las exigencias del bien común de la Humanidad. Vivimos dentro de una interdependencia que no se puede ignorar ni desconocer. La comunidad internacional es un hecho irrebatible que se afirma de día a día $y$ que invita a meditar sobre el destino general del hombre. Y las Naciones Unidas son un feliz compromiso entre la Soberanía nacional y el gobierno del mundo, sin ser una Liga Federal de Estados.

Raúl Ferrero, en el capítulo final El Estado en el plano internacional de su reciente libro - "Derecho Constitucional" (Lima, 1956) - destaca la preeminencia del orden jurídico internacional como la mejor garantía para preservar la paz. Es la única y última barrera entre la paz y la guerra y facilita la ccoperación internacional.

Las líneas generales de las Naciones Unidas son: autodeterminación de los pueblos, igualdad soberana de los Estados, elevación del standard de vida de las masas trabajadoras y universalidad de la organización.

Las Naciones Unidas existen $y$ se vienen afirmando, constituyen el "fortum hall of the world" de gran majestad. Es una organización internacional y una institución que merece el respeto y la confianza del mundo y que nadie, ninguna persona, por irresponsable que sea,'ni ningún gobierno por poderoso que fuere, se atreve a desconocer $y$ que ha capturado la imaginación de la opinión pública del mundo. 
Constituyen una poderosa organización que no solo se interesa en los: aspectos políticos y en los conflictos entre los Estados, sino que trabaja en la cooperación internacional y por el desarrollo económico y la elevación del standard de vida, por los derechos humanos, por facilitar la autonomía a los pueblos bajo tutela, por atender y redistribuir a los dos millones de refugiados, por lograr la codificación del Derecho Internacional orientando la conducta jurídica de hombres y pueblos. Dentro de las limitaciones en las que actúa, las Naciones Unidas vienen cumpliendo, con decisión y eficiencia, los propósitos que figuran en la Carta y que son los siguientes:

Mantener la paz y la seguridad internacionales;

Fomentar las relaciones de amistad entre los pueblos;

Cooperar en la solución de los problemas internacionales: económicos, sociales, culturales y educacionales que afectan a la Humanidad, estimular el respeto por los derechos humanos y las libertades fundamentales.

Los PRINCIPIOS que determinan su acción son:

La igualdad soberana de todos sus miembros;

Todos los Estados Miembros deben cumplir de buena fé las obligaciones de la Carta;

Las controversias internacionales deberón arreglarse por medios pacíficos, absteniéndose de recurrir a la amenaza o al uso de la fuerza;

Las Naciones Unidas no pueden intervenir en los asuntos que son de la exclusiva jurisdicción interna de un Estado;

Ningún Estado podrá ayudar a otro contra el cual las Naciones Unidas han tomado alguna acción preventiva o coactiva.

Conforme se anuncia en el Preámbulo y en el Capítulo I de la Cartar los cinco puntos fundamentales de la acción política de las Naciones Unidas son: 10-Mantenimiento de la paz y de l, a seguridad internacional, 2.-La seguridad colectiva; $3^{\circ}$-Prohibición del uso de la fuerza contra la integridad territorial o la independencia política de un Estado, debiendo utilizarse la fuerza solo en el interés común; $4^{\circ}$--Respeto del derecho internacional y de las obligaciones provenientes o derivadas de Tratados; $5^{\circ}$ - Respeto por la independencia de las naciones $\mathrm{y}$ del derecho de propia determinación $\mathrm{y}$ de su soberanía interna.

El gran principio orientador es la justicia. Las Naciones Unidnas deben procurar el arreglo pacífico de los conflictos dentro de los principios de justicia y mantener la paz, respetando el Derecho de todas las Naciones. $Y$ el hecho que 81 naciones hayan aceptado la Carta, implica una garantía para esos principios y para la paz del mundo.

Las Naciones Unidas no solo son el más hermoso edificio de Nueva York sobre el East River, recortándose sobre el cielo de la gran compópolis, con su hermosa estructura de acero $y$ vidrio, sus 38 pisos y en cuyos corredores, louanges $y$ salas de sesiones, discurren hombres $y$ mujeres venidos de todos los rincones de la tierra y de los siete mares, hablando todas las lenguas y llevando con orgullo los más diversos vestidos, en una perfectas igualdad humana y la más cabal fraternidad. No sólo es una organización 
internacional y un Secretariado. Es una institución que ningún pueblo ní ningún Gobiero pueden ignorcr.

Las Naciones Unidas no son un superestado, sino una organización política $Y$ jurídica internacional con poderes específicos -que nacen de su Carta constitutiva- y con un objetivo determinado: mantener la paz y la seguridad internacional.

Es un instrumento de negociación entre los Gobiemos y para los Gobiernos aunque no puede sustituirse a esos Gobiernos en sus esfuerzos de impedir o prevenir las guerras. Es un experimento de gobierno mundial y todo en la vida, es un continuo experimento.

"Los acontecimientos del año pasado (o sea en 1956) han permitido que se precise la función de las Naciones Unidas en la época actual. La Carta, en su conjunto, no confiere a las Naciones Unidas ninguno de los atributos de un superestado ni de un órgano que pueda actuar sino por decisión de los Estados Miembros. Las Naciones Unidas son más bien un instrumento de negociación entre los Estados $\mathrm{Y}$, en cierta medida, en pro de los Estados. Constituyen también, un nuevo instrumento en el campo de la diplomacia para concertar las actividades de los Estados en apoyo de los objetivos de la Carta. Esta es la función que, desde que se constituyó, ha desempeñado la Organización, a veces con éxito, a veces sufriendo reveses desalentadores". (1)

Es un compromiso entre las medidas conciliadoras, respaldadas por una fuerza militar colectiva que puede convertirse con el tiempo, en un ejército internacional. No es una fórmula sino un sistema. No es un fin en sí mismo sino un instrumento al servicio de la paz internacional. No es un gobiemo mundial pero sí una comunidad naciente que la Carta puedo orientar hacia un orden mundial porque marchando hacia adelante es la mejor forma de sobrevivir. Encarna un sistema de paz y seguridad. autoriza el uso colectivo de la fuerza para resistir la opresión y el empleo de medios conciliatorios y constructivos para prevenir o arreglar un conflicto. No ha solucionado todos los problemas que ha tratado $y$ algunos como el de Hungría, claman al cielo. Pero constituyen un forum mundial de absoluta impar. cialidad, donde todas las partes de una controversia pueden exponer sus puntos de vista, donde todas las naciones pueden dar su opinión en pié de igualdad, en que todas las fases de un problema pueden investigarse con completa objetividad, presentándose una o varias soluciones o compromisos de acuerdo o proporcionar un asesoramiento técnico e imparcial. Es este un nuevo campo de la "diplomacia multilateral". Su principal mérito es servir de instrumento para negociación entre los gobiernos y concentrar una acción conjunta para la realización de los objetivos de la Carta.

Sería preferible aceptar a las Naciones Unidas tales como son: un instrumento, sin duda imperfecto, pero indispensable, del que se valen los Estados para procurar una evolución pacífica hacia un orden mundial más

(1) Introducción a la Memoria Anual del Secretario General de las Naciones Unidas New York, 1957. 
justo y seguro. Las fuerzas dinámicas que actúan en esta etapa de la historia de la humanidad han hecho necesaria una organización mundial. El equilibrio de dichas fuerzas ha impuesto, también los límites dentro de los cuales puede manifestarse, en cada paso, la autoridad de la organización mundial, y más allá de los cuales, solo será posible alcanzar algún progreso, cyando el equilibrio de las fuerzas lo permita mediante un proceso de evolución orgánica de las normas de derecho que prevalecen en la sociedad de naciones.

Para dicho proceso de ajuste hace falta tiempo. Los sistemas de alianza establecidos, paralelamente, a las Naciones Unidas en reconocimiento del equilibrio de fuerzas existentes pueden resultar útiles. Sin embargo, hay que convenir en que tales sistemas de alianza, como otros procedimientos tradicionales de diplomacia y defensa de los intereses nacionales, tienen un valor limitado en tanto que salvaguardan la seguridad y bienestar pre sentes y futuros de nuestros países. Las naciones $y$ los grupos de naciones ya no podrían jamás vivir y arrogarse la facultad de decidir en asuntos internacionales por medios que antes eran usuales.

En la actualidad, es indispensable moderar los conflictos entre las naciones y no agravarlos. Si se las emplea convenientemente, las Naciones Unidas pueden constituir un instrumento de reconciliación mejor que otros de que puedan disponer los Estados Miembros. Los distintos intereses $y$ aspiraciones del Mundo se dan cita en su recinto, teniendo como base común, la Carta. Es posible que los conflictos persistan por largo tiempo sin que se convenga en una solución, y que grupos de Estados defiendan activamente intereses particulares y regionales. No obstante, la tendencia en las Ncciones Unidas es de moderar o reducir las diferencias.

Las Naciones Unidas son el símbolo de la unidad moral del mundo y guardián de la paz e inclusive Rusia y sus satélites prentenden actuar de acuerdo con la Carta.

Las Naciones Unidas ni hacen ni pueden hacer milagros, pero ha sido de enorme utilidad en lo que llamaríamos la estrategia de la paz. No pueden solucionar todos los problemas internacionales ni arreglar todos los conflictos pero representan el deseo de paz y de justicia al que aspira la humanidad entera $y$ que todas las naciones del mundo han aceptado, cuando menos en principio. La paz, por otra parte, no implica ausencia de conflictos ni de problemas sino que se eviten las guerras, totales o locales, reduciendo las tensiones y previniendo las guerras en potencia. Desde su sede general no puede dictar órdenes como lo solía hacer la Roma Imperial, ni disponer de legiones. Pero es un gran centro de fuerza moral e intelectual y un sustituto para las batallas, una lucha ideológica pero en que no se derrama sangre; no deja ni huérfanos, ni viudas, ni ciudades destruídas. El record de sus realizaciones en los primeros años de existencia es impresionante, sobre todo si se considera las dificultades que ha vencido. Desde que fué establecida ha desempeñado un papel de importan. cia innegable en todos los esfuerzos realizados para matener la paz y solucionar las crisis que se han producido - independencia de Indonesia, armisticios en Cachimira, Corea, Palestina y Corea - y debido a su carác- 
ter universal, puede servir a una política de reconciliación. En los últimos años, ha logrado organizar la Agencia Internacional de la Energía Atómica, crear la Fuerza de Emergencia de las Naciones Unidas, restablecer el tráfico del Conal de Suéz y crear un Fondo de Desarrollo Económico y se apresta a echar las bases para el uso pacífico del Espacio Sideral. Dentro de la Organización, todos los hombres son libres e iguales y todas las Naciones gozan de derechos inalienables. $Y$ pese a todas las imperfecciones responde a la esperanza universal de paz y justicia, un sueño feliz en trance de realizarse en medio de sus altas y bajas. La vida internacional está tan íntimamente ligada a las Naciones Unidas que si fuera disuelta, reviviría bajo otro nombre.

Si vivimos una paz difícil, una paz sin seguridad, no proviene de la estructura de las Naciones Unidas ni de los defectos que pudiera tener la Organización ni de sus limitaciones, sino que vivimos en una época tensa $y$ de cambios revolucionarios en la vida del hombre y en las relaciones entre los pueblos como son el descubrimiento de la energía atómica, la conquista del espacio sideral, el renacer de Asia, el despertar de Africa. $Y$, como lo ha dicho el Presidente Eisenhower, constituye la conciencia colectiva de la Humanidad y la suprema esperanza de la paz aunque el camino que tenía por delante sea largo, difícil y peligroso. Es la única salvaguardia de la paz.

El éxito y la sobrevivencia de las Naciones Unidas está ligado estructuramente al futuro de nuestra civilización. Es un nuevo tipo de diplomacia multilateral $Y$, repitiendo el título de un editorial del New York Times, concluíremos llamándola "las indispensables Naciones Unidas" y si el Evangelio llama hijos de Dios a los obreros de la paz, las Naciones Unidas, merecen la bendición del Altísimo.

Los grupos regioncles existentes son:

Organización de los Estados

Americanos O. E. A.
Las 21 Naciones

Americanas.

Argentina, Bolivia, Brasil, Colombia' Costa Rica, Cuba, Chile, Ecuador, El Salvador, Estados Unidos, Guatemala, Haití, Honduras, México, Nicaragua, Paniamá, Paraguay, Perú, República Dominicana, Uruguay, Venezuela. 
Liga de

Estados Arabes

Pacto de

Bagdad

Unión Occidental

Comunidad Británica

de Naciones

Commonwealth

Pacto de

Varsovia

Organización del Sud-Este de Asia S.A.T.O.
Arabia Saudita

Egipto-Siria - (Federación de la

República Ārabe Unida)

Libia

Líbano

Iraq

Jordania,

Marruecos

Sudán

Tunisia

Yemen

Gran Bretaña

Turquía

Jordania,

Irán

Pakistón

Gran Bretaña

Francia

Bélgica

Holanda

Luxemburgo

Gran Bretaña

Canadá

Australia

Nueva Zelondia

India

Ceylán

Pakistán

Unión Sud Africana

Ghana

Malaya

Rusia Soviética

Polonia

Hungría

Bulgaria

Checoeslovaquia

Albania

Rumanía

Estados Unidos

Gran Bretaña

Francia

Nueva Zelandia

Filipinas

Tailandia

Pakistán 
Bloque
Escandinavo

Benelux

Comisiones

Económicas de

Naciones Unidas

Conferencia de

Bandug

Euroton

Organización del

Tratado del Atlóntico Norte

NATO)
Dinamarca

Suecia

Noruega

Islandia

Luxemburgo

Holanda

Bélgica

América Latina (CEPAL)

Asia y Extremo Oriente

Europa

Africa (recién creada).

China Comunista

India

Pakistón

Vietnam del Norte

Birmania

Ceylón

Indonesia

Francia

Alemania

Italia

Bélgica

Holanda

Luxemburgo

Estados Unidos

Inglaterra

Francia

Bélgica

Luxemburgo

Holanda

Dinamarca

Alemania Occidenta]

Noruega

Portugal

Italia

Turquía

Islandia

Canadá 


\section{Reforma del Código Penal Alemán}

En el discurso que el ex-Ministro de Justicia Dr. h.c. Fritz Neumayer pronunció, el 21 de mayo de 1957, en la Universidad de Friburgo, al recibir el grado de Doctor honoris causa, dijo, entre otras cosas, lo siguiente respecto a la gran reforma de la parte general del Código Penal Alemán:

"En el proyecto de la parte general de un futuro Código Penal, con el cual la obra de reforma ha llegado a una fase importante, la Ciencia ha tenido una parte destacada. En la Comisión citada por mí se han reunido ilustres representantes de todos los grupos que, de distintos modos. se ocupan del Derecho penal: jueces y fiscales, abogados y funcionarios ministeriales, diputados y también profesores. Siempre he considerado como la coronación de mi actividad en el Ministerio de Justicia presidir esta Comisión y poder observar y encauzar en ciena forma la fecunda disparidad y armonía entre el poder legislativo y el ejecutivo, entre la Ciencia y la próctica.

"En esta cooperación, todos los que han participado han respondido admirablemente a las tareas que les correspondieron en la obra de reforma. Esto se refiere, y no en último término, a la Ciencia del Derecho Penal, que contribuyó decisivamente a la creación de los conceptos fundamentales y que supo responder a las exigencias de la práctica nacidas de la experiencia. Estas no son meras palabras. Quizás sepáis, y con esto me fijo en la idea fundamental de nuestro proyecto, que la Gran Comisión ha proclamdo resueltamente el principio del Derecho Penal de culpabilidad que, como pienso exponer más adelante, informa todo el proyecto de la parte general. Esta proclamación no habría sido posible sin la ayuda de la Ciencia. Al decir esto no pienso sólo en el Derecho en sí sino también en la moderna Filosofía, en la Antropología y en las Ciencias Naturales cuyo desarrollo parecía privar de base todavía en el siglo pasado a un Derecho penal de culpabilidad. Hoy las cosas son distintas. No necesito entrar en detalles pues hace pocos meses que en esta Universidad el profesor Jeschek, que pertenece también a la Gran Comisión de Derecho Penal, ha dicho convincentemente, en su magnífico discurso sobre el hombre de nuestro tiempo. 